\title{
Building on Gleiter: The Foundations and Future of Deformation Processing of Nanocrystalline Metals
}

\begin{abstract}
SUVEEN N. MATHAUDHU
In 1989, fueled by his prior reports and findings, Prof. Herbert Gleiter published a seminal work on the synthesis, processing, and possibilities for nanocrystalline materials. This spark exploded into the field of bulk nanocrystalline metals by severe plastic deformation processing, with the primary driver being attaining the ultimate strength of a metal through refinement of the grain sizes to a level approaching the theoretically possible limits. This paper will briefly explore the historical development of SPD and based on Turnbull's strategy of "energizing and quenching" materials to attain a desirable metastable state, present thoughts on incipient-related areas of exploration, including thermal stabilization through solute additions, the role of trace impurities and interstitials, the smallest grain size achievable (both theoretically and practically), and the captivating yet hazy character and role of the grain boundary. Lastly, some new approaches to making and then controlling the behavior of nanocrystalline materials will be presented. At each stage, opportunities for future study will be raised. On the 50th Anniversary of Metallurgical and Materials Transactions $A$, it is hoped that this report will build off the seed planted by Gleiter and inspire new work and collaborations in the years to come.
\end{abstract}

https://doi.org/10.1007/s11661-020-06031-5

(C) The Minerals, Metals \& Materials Society and ASM International 2020

\section{HARBINGERS AND ANTECEDENTS*}

\begin{abstract}
*This clever Introduction subtitle is borrowed from a classic $\mathrm{Me}$ tallurgical Transactions A paper titled "A Brief History of Dislocation Theory" by Hirth ${ }^{[3]}$ which has served as an inspiration and model for the current paper.
\end{abstract}

THE rote history of "nanotechnology" is frequently initiated through a discussion of the pseudo-prophetic lecture of Prof. Richard Feynman at Caltech in 1959, which postulated the scientific and technological advancements that could be achieved through manipulation of condensed matter at the atomic scale. However, to many in the materials science and engineering community, the foundational concepts of nanostructured materials tie back to a different landmark lecture, one by Prof. Herbert Gleiter titled "Materials with Ultra-Fine Grain Sizes" in 1981 at the Second Risö

SUVEEN N. MATHAUDHU is with the Materials Science and Engineering Program, University of California, Riverside, CA 92521 and with the Department of Mechanical Engineering, University of California, Riverside, CA 92521 and also with the Energy and Environment Directorate, Pacific Northwest National Laboratory, Richland, WA 99354. Contact e-mail: smathaudhu@engr.ucr.edu

Manuscript submitted May 14, 2020; accepted September 18, 2020.

Article published online October 14, 2020
International Symposium on Metallurgy and Materials Science in Roskilde, Denmark. ${ }^{[1]}$ In that lecture, Gleiter posited and advanced the hypothesis that when the volume fraction of atoms near a crystal boundary in a material approaches $50 \mathrm{pct}$, the properties would fundamentally change. In his 1972 textbook, Ziman ${ }^{[2]}$ presented a predominant assumption used within the solid-state physics community; that crystals were nearideal solid with very few atoms adjacent to a boundary $\left(1\right.$ in $\left.10^{8}\right)$. Ziman recognized that crystalline defects and dislocations (whose existence themselves had remained controversial until their first observation in $1956^{[3]}$ ), and impurities would disturb the pristine order of a crystal, yet noted that "Such imperfections give rise to many interesting physical phenomena, but we shall ignore them, except incidentally, in the present discussion." Gleiter's lecture and his subsequent works employed the opportunity to uniquely explore the ignored "interesting physical phenomena" in grain boundaries as the crystal size decreases to nanometer length scales, and ignited the imaginations of the broad materials science community. ${ }^{[4]}$ A short communication from Gleiter ${ }^{[5]}$ relayed the disruptive nature of his proposition at the time:

[Here is] the reaction of a very well-known colleague when I proposed for the first time the idea to generate materials which consist of 50 pct or even more of interfaces so that interfaces are now used to generate solids with a new kind of atomic structure and hence 
new properties. During my presentation, he left the room and shouted loudly: "He was already crazy in the past but now he is all gone." This colleague was educated during a time when the perfect crystals were the only acceptable structure of matter and defects were just to be "dirt." Now somebody comes and suggests to produce new kind of solids made up of "dirt." That was too much for him.Forthcoming, there will be more discussion on the "dirt," but for now let's return back to Gleiter's fundamental thesis: the presence of certain defects, such as edge dislocations and vacancies, may alter the local atomic density of the surrounding region in a crystal lattice, and in the case of a grain boundary, this occurs based on the misorientation and incompatibilities between the lattices of adjacent crystals. Thus, for different crystal orientations, crystal structures, and crystal inclinations, a wide variety of grain boundary structures exist. If this is assumed to be true, in a material where a large percentage of atoms are adjacent to a defect core, then the atomic description of the material depends on the defect core structures. As the grain size decreases, as in nanocrystalline (NC) materials, the volume fraction of grain boundaries, vacancies, dislocations, and other defects also increase. Figure $1 .{ }^{[6]}$ presents an analysis by Kim et al. for a cubic grain with a typical grain boundary thickness of $\sim 1 \mathrm{~nm}$, and from it, some important observations can be made. Firstly, the increase in the volume fraction of defects does not noticeably increase until the grain size is reduced to 10 seconds of nanometers.

To reach the 50 pct value, Gleiter stated that $10^{19}$ grain boundaries per $\mathrm{cm}^{3}$ would be needed, and this would occur at grain sizes $<10 \mathrm{~nm} \cdot{ }^{[7]} \mathrm{He}$ surmised that at these small grain sizes, the microstructure would have the requisite number of grain boundaries, but also highly strained atomic lattice regions at these boundaries, due to the misfit and misorientation between the crystal lattices. Figure 2 illustrates this concept for a fully relaxed, simulated gold nanocrystalline material. The black circles are the "crystallite regions," the open circles are the "grain boundary" regions, and the atoms were constructed using a Morse potential. ${ }^{[7]}$ In this case, the grain boundary core defect region is clearly dependent on the misorientation of the nanocrystals and inclination boundary. ${ }^{[7,8]}$ Note that in this simulation, the crystallites are perfectly crystalline and at equilibrium; however, the interfaces are lower density and highly strained. This model suggests that the grain structure is comprised of a periodic arrangement of atoms, and as the grain size reduces, these boundaries introduced defect cores at the grain interfaces. Gleiter

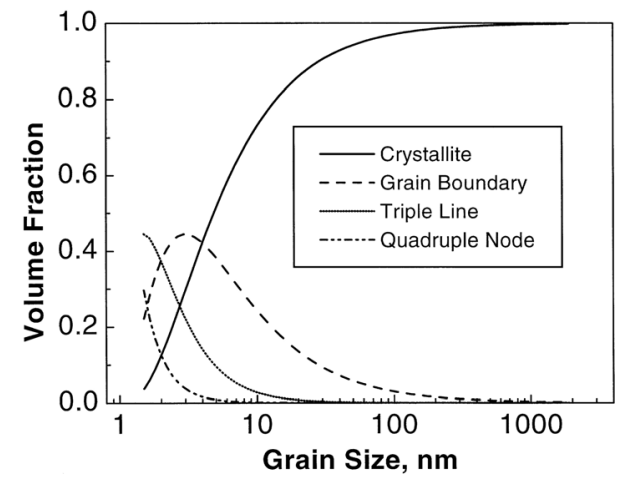

Fig. 1-Volume fractions of microstructural components as a function of grain size for a model, cubic unit cell, assuming a $1 \mathrm{~nm}$ boundary. Reprinted from Ref. [6] with permission from Elsevier.

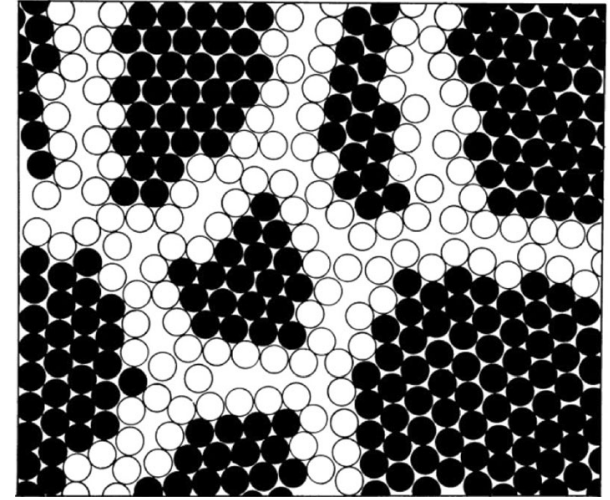

Fig. 2-A fully relaxed 2D simulation of nanocrystalline gold, assembled using a Morse potential. The black atoms are the crystallite and the open atoms compose the grain boundaries. ${ }^{[7,8]}$ Reprinted from Ref [7] with permission from Elsevier.

pointed out that the interface was not a "liquid-like glassy" layer that would originate from thermally induced disorder. In reality, the vast majority of nanocrystalline metals are quite different from the simple case proposed by Gleiter and shown in Figure 2. There is yet to be any observed evidence of 50 pct of a material's atoms being located in a boundary for a nanocrystalline material, and certain defects, such as twins, screw dislocations and stacking faults do not substantially affecting the local density of atoms if at all (in the case of twinning). Yet, the simple, profound observation that grain boundary defects, when in a high enough volume fraction, are the principal cause of the fundamental property changes from those observed in a perfect lattice, has continued to resonate in the scientific community.

In 1989, Gleiter published a seminal review ${ }^{[7]}$ that further served as a watershed moment in the materials science community due to its vision and breadth. ${ }^{[9-11]}$ The paper was of key interest to the metallurgy community, who since the 1950's had been pushing to refine grain structures to a size wherein the ideal strength $(\sim G / 10)^{[12]}$ (and later refined to $\left.\sim G / 30\right)^{[13-15]}$ could be approached per the observations of the Hall-Petch relationship ${ }^{[16-18]}\left(\sigma_{y}=\sigma_{o}+k d^{-1 / 2}\right)$, where $\sigma_{y}$ is the yield point, $\mathrm{d}$ is the grain size, and $\sigma_{\mathrm{o}}$ and $k$ are experimentally determined constants based on chemistry and microstructure. Cordero et al. have performed a useful and exhaustive analysis that has aggregated six decades of Hall-Petch literature for pure metals and have also performed a critical analysis of the strengthening models used to mechanistically substantiate Hall-Petch scaling effects. ${ }^{[19]}$ Similarly, Armstrong presented a comprehensive picture of the Hall-Petch relationship over the past 60 years. ${ }^{[20]}$

While the initial work done by Gleiter and colleagues largely focused on the synthesis of NC metals from gas or liquid precursors, the metals processing community was fast to follow with alternative approaches that sought to realize "bulk" deformation processing methods to achieve high-strength nanocrystalline (NC) (10 to 
$100 \mathrm{~nm}$ grain size) or ultrafine-grained (UFG) (100 to $1000 \mathrm{~nm})$ materials. ${ }^{[21-25] * *}$ In the last four decades, the could enable expanded property limits and avoid common trade-offs, such as strength vs ductility. Section IX summarizes the paper with brief concluding thoughts.

\section{THE CURRENT STATE OF SEVERE PLASTIC DEFORMATION APPROACHES FOR NANOCRYSTALLIZATION}

At the most fundamental level, our ability to manipulate materials into useful things has hinged on our ability to process them away from equilibrium, and therefore manipulate and trap a material in a metastable state. In 1981, the same year as Gleiter's lecture, Turnbull ${ }^{[27]}$ presented a paper on "Metastable Structures in Metallurgy"

\footnotetext{
${ }^{\dagger}$ This is yet another foundational and rousing Metallurgical Transactions $A$ paper ${ }^{[27]}$ presented by Campbell for the 1980 Edward DeMille Campbell Memorial Lecture. He identified some prescient "Problems and Opportunities in Metastable Structure and Synthesis," including impurity trapping in crystals, superheating in laser pulsing, compositionally modulated films for atomic transport, and dispersion by plastic deformation to explore both the limit of interfacial densities and dislocation content, and dislocation core properties. Many of these concepts will be touched on herein.
}

another distinction between a metallurgist and condensed matter physicist is the former's focus on metastability, as metals and alloys "may be said to be morphologically metastable because of their considerable density of such extended imperfections as intergrain and interphase boundaries and dislocations." Turnbull presented the idea in terms of "energizing and quenching." The energizing component essentially creates a "driven system" ${ }^{[28]}$ by bringing the material to a state away from equilibrium, with the operative mechanism here being the storing of the mechanical energy by cold-working of the metal in the form of dislocations. The quenching component was indicated by Turnbull to generally be due to cooling at a specific rate, but more broadly, the restoration of a local equilibrium state following the energization, with the cognition that many such local intermediate metastable states may exist and that quenching may "freeze" this "configurationally frozen" metastable state.

In the $\sim 40$ years since Gleiter's lecture, the study of methods to fabricate "bulk" NC materials by plastic deformation has been a well-trodden path. Starting with the mechanical milling approach discussed by Gleiter, ${ }^{[7]}$ an unending number of processing approaches to "energize and quench" metallic materials have been developed with the goal of refining grain sizes to the nanoscale while lending them high-angle grain boundaries, some modicum of stability and, primarily, increased strength. Some of these methods are shown in Figure 3, and for brevity, Table I presents an incomplete list of review articles and key papers for each of these methods along with other themes studied in this paper. The energizing driving force in each of these methods is the introduction of a high number of defects through the imposition of intense plastic 


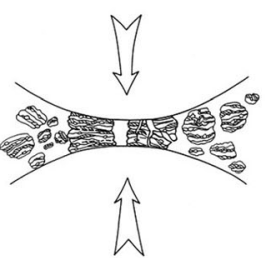

(a)

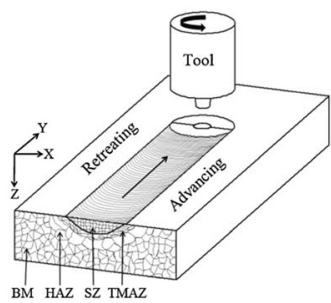

(f)

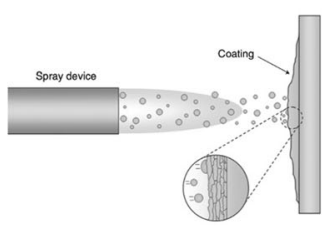

(b)

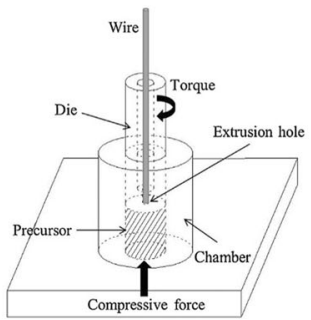

(g)

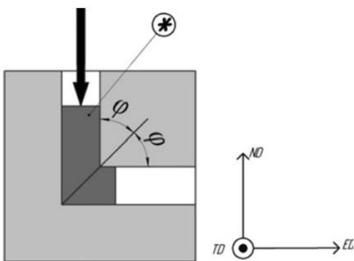

(c)

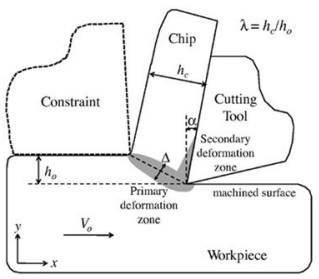

(h)

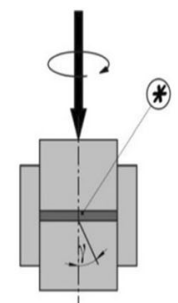

(d)

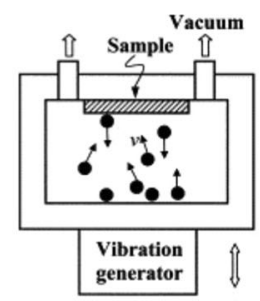

(i)

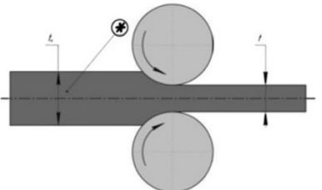

(e)

Fig. 3-Typical deformation processing methods for obtaining nanocrystalline $(<100 \mathrm{~nm})$ or ultrafine $(100$ to $1000 \mathrm{~nm})$ grains: $(a)$ mechanical milling $(\mathrm{MM}),{ }^{[21,22]}(b)$ cold-spray $(\mathrm{CS}),{ }^{[37]}(c)$ equal-channel angular extrusion/pressing (ECAE/ECAP), ${ }^{[38,39]}(d)$ high-pressure torsion $(\mathrm{HPT}),{ }^{[38,40]}(e)$ accumulative roll bonding $(\mathrm{ARB}),{ }^{[38]}(f)$ friction stir processing (FSP) ${ }^{[41]}(g)$ friction extrusion $(\mathrm{FE}),{ }^{[42]}(h)$ large-strain extrusion machining (LSEM) ${ }^{[43]}$ (i) surface mechanical attrition treatment (SMAT), ${ }^{[4]}$ and $(j)$ surface mechanical grinding treatment (SMGT). ${ }^{[45]}$ Reprinted from Refs ${ }^{[22,37,38,37-38]}$ with permission from Elsevier.

deformation in the form of plastic work. The "quench" often occurs through the re-organization of the defects into a lower-energy (albeit still metastable) nanocrystalline or ultrafine-grained thermodynamic state. All other factors being equal, it is generally observed that total strain, alloying and temperature play the more critical roles on refinement to the nanoscale. The higher the processing temperature, the larger the grain size, and therefore processing at lower temperatures, or cooling the material post-processing (sometimes at cryogenic temperatures are often studied in attempts to introduce more defects while, at the same time, suppressing thermal recovery mechanisms. ${ }^{[23,29-32]}$ A formal definition of "severe plastic deformation" (SPD) has since been developed ${ }^{[33,34]}$ :

1. SPD Processing: Any metal forming operation with extensive hydrostatic pressure that may be used to impose a very high strain on a bulk solid without significant changes in the overall dimension and having the ability to produce exceptional grain refinement.

2. Bulk ultrafine-grained (UFG) materials: Materials having a homogenous, equiaxed microstructure with average grain sizes less than $1000 \mathrm{~nm}$, and the majority of boundaries having large angles of misorientation.

This definition has changed over time as new materials and microstructures have been observed, but has generally stayed fairly constant. As a caveat, microstructural evolution pathways to achieve nanocrystalline metals have been explored by many and can vary based on alloying, crystal structure, stacking fault energy, ${ }^{[35]}$ intensity and directionality of applied strain, strain rate, processing temperature, precipitates, and a host of other factors. Cao et al. ${ }^{[36]}$ have collected the first systematic review of severe plastic deformation-induced microstructural evolution routes to $\mathrm{NC}$ (and UFG) metals, to which the reader can refer for a deeper understanding of SPD-induced microstructural evolution. However, in the interest of presenting the historical development of our understanding of microstructural evolution during severe plastic deformation, the sequential presentation of some general theories based on the knowledge of the time will be given.

An early conjectured model of nanocrystallization (largely for high-stacking fault energy fcc materials) during high-energy milling (intense cyclic deformation at highstrain rates) was summarized into three stages by Fecht 
Table I. Foundational Articles on Nanocrystalline Metals Processing, Microstructure, and Properties

\begin{tabular}{|c|c|c|c|}
\hline Authors & Year & Title & References \\
\hline \multicolumn{4}{|l|}{ Nanocrystalline Materials } \\
\hline Gleiter & 1989 & Nanocrystalline materials & 7 \\
\hline Suryanarayana & 1995 & Nanocrystalline materials: a critical review & 9 \\
\hline Suryanarayana and Koch & 2000 & Nanocrystalline materials: current research and future directions & 11 \\
\hline \multicolumn{4}{|l|}{ Severe Plastic Deformation Methods } \\
\hline Koch & 1997 & $\begin{array}{l}\text { Synthesis of nanostructured materials by mechanical milling: } \\
\text { problems and opportunities }\end{array}$ & 21 \\
\hline Murty and Ranganathan & 1998 & Novel materials synthesis by mechanical alloying/milling & 96 \\
\hline Valiev, Islamgaliev, Alexandrov & 2000 & Bulk nanostructured materials from severe plastic deformation & 24 \\
\hline Suryanarayana & 2001 & Mechanical alloying and milling & 22 \\
\hline Mishra and Ma & 2005 & Friction stir welding and processing & 257 \\
\hline Valiev and Langdon & 2006 & $\begin{array}{l}\text { Principles of equal-channel angular pressing as a processing tool } \\
\text { for grain refinement }\end{array}$ & 39 \\
\hline Witkin and Lavernia & 2006 & $\begin{array}{l}\text { Synthesis and mechanical behavior of nanostructured materials via } \\
\text { cryomilling }\end{array}$ & 23 \\
\hline Zhilyaev and Langdon & 2008 & $\begin{array}{l}\text { Using high-pressure torsion for metal processing: fundamentals } \\
\text { and applications }\end{array}$ & 40 \\
\hline Estrin and Vinogradov & 2013 & $\begin{array}{l}\text { Extreme grain refinement by severe plastic deformation: a wealth } \\
\text { of challenging science }\end{array}$ & 38 \\
\hline Langdon & 2013 & $\begin{array}{l}\text { Twenty-five years of ultrafine-grained materials: achieving excep- } \\
\text { tional properties through grain refinement }\end{array}$ & 34 \\
\hline Champagne and Helfritch & 2016 & The unique abilities of cold spray deposition & 259 \\
\hline Vinogradov and Estrin & 2018 & $\begin{array}{l}\text { Analytical and numerical approaches to modelling severe plastic } \\
\text { deformation }\end{array}$ & 158 \\
\hline \multicolumn{4}{|c|}{ 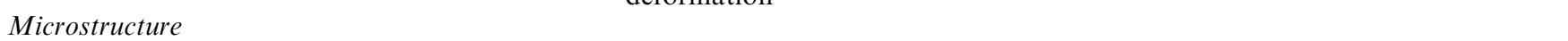 } \\
\hline Zhu, Liao and $\mathrm{Wu}$ & 2012 & Deformation twinning in nanocrystalline materials & 52 \\
\hline $\begin{array}{l}\text { Sauvage, Wilde, Divinski, Horita and } \\
\text { Valiev }\end{array}$ & 2012 & $\begin{array}{l}\text { Grain boundaries in ultrafine grained materials processed by } \\
\text { severe plastic deformation and related phenomena }\end{array}$ & 225 \\
\hline $\begin{array}{l}\text { Raabe, Herbig, Sandlöbes, Li, Tytko, } \\
\text { Kuzmina,Ponge and Choi }\end{array}$ & 2014 & $\begin{array}{l}\text { Grain boundary segregation engineering in metallic alloys: a } \\
\text { pathway to the design of interfaces }\end{array}$ & 159 \\
\hline Peng, Gong, Chen, Liu & 2016 & $\begin{array}{l}\text { Thermal stability of nanocrystalline materials: thermodynamics } \\
\text { and kinetics }\end{array}$ & 109 \\
\hline Ma and Zhu & 2017 & $\begin{array}{l}\text { Towards strength-ductility synergy through the design of } \\
\text { heterogenous nanostructures in metals }\end{array}$ & 254 \\
\hline Cao, Ni, Liao, Song and Zhu & 2018 & $\begin{array}{l}\text { Structural evolutions of metallic materials processed by severe } \\
\text { plastic deformation }\end{array}$ & 36 \\
\hline Wilde and Divinski & 2019 & $\begin{array}{l}\text { Grain boundaries and diffusion phenomena in severely deformed } \\
\text { materials }\end{array}$ & 227 \\
\hline Bachmaier and Pippan & 2019 & $\begin{array}{l}\text { High-pressure torsion deformation induced phase transfomations } \\
\text { and formations: new materials combinations and advanced } \\
\text { properties }\end{array}$ & 228 \\
\hline An, Wu, Wang and Zhang & 2019 & $\begin{array}{l}\text { Significance of stacking fault energy in bulk nanostructured } \\
\text { materials: insights from } \mathrm{Cu} \text { and its binary alloys as model systems }\end{array}$ & 35 \\
\hline $\begin{array}{l}\text { Cantwell, Frolov, Rupert, Krause, Marvel, } \\
\text { Rohrer, Rickman and Harmer }\end{array}$ & 2020 & Grain boundary complexion transitions & 208 \\
\hline \multicolumn{4}{|l|}{ Mechanical Behavior } \\
\hline Mohamed and $\mathrm{Li}$ & 2001 & $\begin{array}{l}\text { Creep and superplasticity in nanocrystalline materials: current } \\
\text { understanding an future prospects }\end{array}$ & 60 \\
\hline Kumar, Van Swygenhoven and Suresh & 2003 & Mechanical behavior of nanocrystalline metals and alloys & 150 \\
\hline $\begin{array}{l}\text { Wolf, Yamakov, Phillpot, Mukherjee and } \\
\text { Gleiter }\end{array}$ & 2005 & $\begin{array}{l}\text { Deformation of nanocrystalline materials by molecular-dynamics } \\
\text { simulation: relationship to experiments? }\end{array}$ & 193 \\
\hline Meyers, Mishra and Benson & 2006 & Mechanical properties of nanocrystalline materials & 62 \\
\hline Dao, Lu, Asaro, De Hosson and Ma & 2007 & $\begin{array}{l}\text { Toward a quantitative understanding of mechanical behavior of } \\
\text { nanocrystalline metals }\end{array}$ & 54 \\
\hline Padilla and Boyce & 2010 & A review of fatigue behavior in nanocrystalline materials & 61 \\
\hline Armstrong & 2014 & 60 years of Hall-Petch: past to present nano-scale connections & 20 \\
\hline Cordero, Knight and Schuh & 2016 & $\begin{array}{l}\text { Six decades of the Hall-Petch effect-a survey of grain-size } \\
\text { strengthening studies on pure metals }\end{array}$ & 19 \\
\hline Ovid'ko, Valiev and Zhu & 2018 & $\begin{array}{l}\text { Review on superior strength and enhanced ductility of metallic } \\
\text { nanomaterials }\end{array}$ & 63 \\
\hline Spearot, Tucker, Gupta and Thompson & 2019 & $\begin{array}{l}\text { Perspective: mechanical properties of stabilized nanocrystalline fcc } \\
\text { metals }\end{array}$ & 108 \\
\hline
\end{tabular}


Table I. continued

\begin{tabular}{llll}
\hline Authors & Year & \multicolumn{1}{c}{ Title } & References \\
\hline Wu and Fan & 2020 & $\begin{array}{l}\text { An overview of tailoring strain delocalization for strength-ductility } \\
\text { synergy } \\
\text { The Hall-Petch and inverse Hall-Petch relations and the hardness } \\
\text { of nanocrystalline metals }\end{array}$ \\
Naik and Walley & 2020 & 57 & 185 \\
\hline
\end{tabular}

et al. and other researchers, ${ }^{[21,46,47]}$ but was found by Hansen and Mehl to be indicative of the general evolution observed in other severe plastic deformation processes ${ }^{[48] \text { : }}$ :

\begin{abstract}
${ }^{\ddagger}$ In 2001, Niels Hansen received the Robert F. Mehl award and presented this Metallurgical and Materials Transaction A paper on "New Discoveries in Deformed Metals." Hansen specifically addresses nanocrystallization via severe plastic deformation and whether the 100 to $200 \mathrm{~nm}$ grain sizes observed represent a saturation in $S_{\mathrm{v}}$ (boundary area per unit volume). He postulated that pure metals may recover/ recrystallize quickly at large strains unless suppressed by addition of other elements (a topic we will return to).
\end{abstract}

1. high-energy ball milling results in the formation of narrow ( 0.1 to $1 \mu \mathrm{m}$ wide) shear bands composed of a high-density of networked dislocations, followed by

2. an increased atomic strain accommodated by dislocation annihilation, recombination and rearrangement into low-angle nanocrystalline subgrains, and subsequent refinement of the grains due to continuous shear banding until dislocation-free grains are generated throughout, and then

3. random orientation of the grain boundaries and no further refinement is possible (steady state); further deformation is proposed to be accommodated through grain boundary sliding or grain boundary diffusion. This proposition was based on the observation of dislocation-free grains, which was later supported by a theory from Arzt. ${ }^{[49]}$

This phenomenology for microstructural evolution was expanded to include a suggestion by $\mathrm{He}$ and Lavernia ${ }^{[50]}$ on the possibility of repeated fatigue fracture and cold-welding during ball milling. Xun et al. ${ }^{[51]}$ then presented the multi-scale theory for microstructural evolution during high-energy milling, as shown in Figure 4.

Since this general model was developed, many other more nuanced and informed microstructural evolution pathways to grain refinement have been reported ${ }^{[36]}$ and many other potentially beneficial microstructures (such as twinning and the formation of nanotwinned regions ${ }^{[52,53]}$ ) have been investigated. More so, the general model presented in Figure 4 has been observed to be most applicable to fcc materials with high-stacking fault energies. The differences in refinement mechanisms can vary based on crystal structure (much less is known about grain refinement in bcc and hep materials), and even within fcc materials, the microstructural evolution depends on the stacking fault energy (SFE), and the effect of SFE on the twinning/detwinning behaviors. ${ }^{[36]}$

Irrespective of the microstructural evolution pathway taken, the ability to refine the grains towards the nanoscale via SPD methods has been amply demonstrated, along with the expected concurrent improvements in strength. ${ }^{[2,54]}$ Materials processed by SPD methods have also been found to have exceptional combinations of strength and ductility, ${ }^{[55-57]}$ high-strain rate properties, ${ }^{[58,59]}$ creep resistance, ${ }^{[60]}$ and fatigue properties ${ }^{[61]}$ based on a variety of SPD-induced features outside of the grain size alone. These and other mechanisms and properties have been well covered in reviews by Meyers et al. ${ }^{[62]}$ and Ovid'ko et al. ${ }^{[63]}$ As such, the focus for this study will return to the original guiding question: what effects do the grain size and boundary have on the strengthening of nanocrystalline metals?

\section{LOW ON ENERGY: THERMODYNAMIC (AND KINETIC) PATHWAYS TO STABILIZATION}

Key to any property improvements is the underlying expectation that the grain size remain nanocrystalline under service conditions. Upon the journey to ambient or elevated homologous temperatures, thermal energy and/or deformation ${ }^{[64-66]}$ can perturb the delicate metastable nanocrystalline state, which often brings decreases in strength via grain growth to a larger, more thermodynamically preferable size ${ }^{[67-74]}$ In the absence of extrinsic stabilization, the grains grow and strength properties are lost. In Figure 5, Weissmüller ${ }^{[75]}$ presents a schematic that illustrates two alloy states proposed by Gleiter, ${ }^{[7]}$ but includes a new principle where solutes with large enthalpies of segregation have energetically minimized the specific grain boundary energy through segregation to the grain boundary. Weissmüller's studies ${ }^{[75-77]}$ combined with work by Kircheim, ${ }^{[78]}$ Krill et al., ${ }^{[79]}$ Hong et al. ${ }^{[80]}$ and Gao et al. ${ }^{[81]}$ set the stage for the recent meteoric rise in interest in thermodynamic approaches to grain boundary stabilization. But what then of fundamental concepts of the suppression of grain growth, such as solute drag, as developed by Cahn? ${ }^{[82]}$ Kircheim supposed that the prevalent kinetics of grain coarsening by solute drag theory do account for a steady-state grain size (a concept we will return to later), but that this grain size was a direct consequence of the metastable equilibrium predicted by Weissmüller. In his own work. Krill et al. generally supported Weissmüller's theory, but rightly qualified that it would not be fully valid if all the solutes segregated 

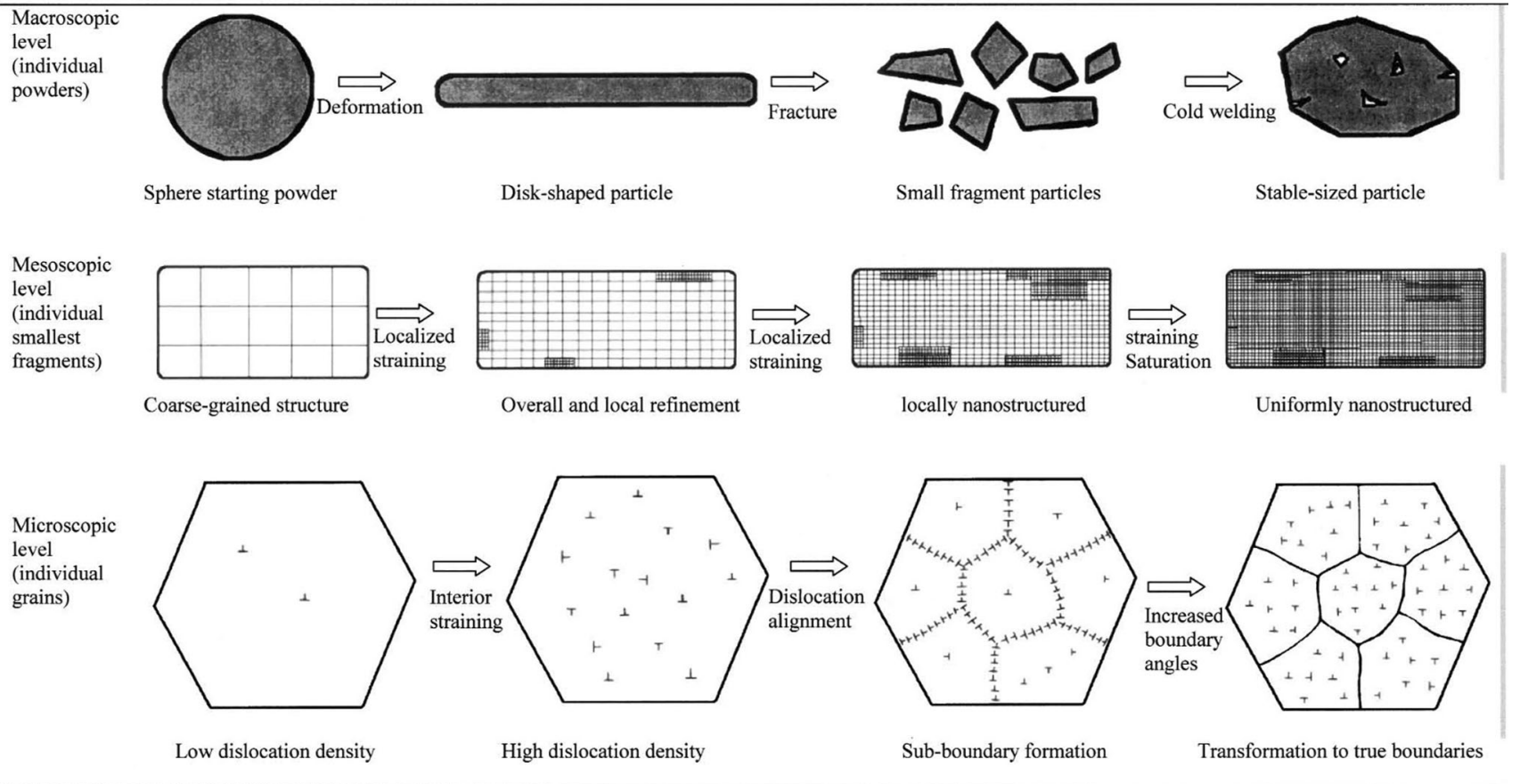

Fig. 4-Schematic illustrations of proposed grain refinement mechanisms during mechanical milling on various structural length scales. ${ }^{[51]}$
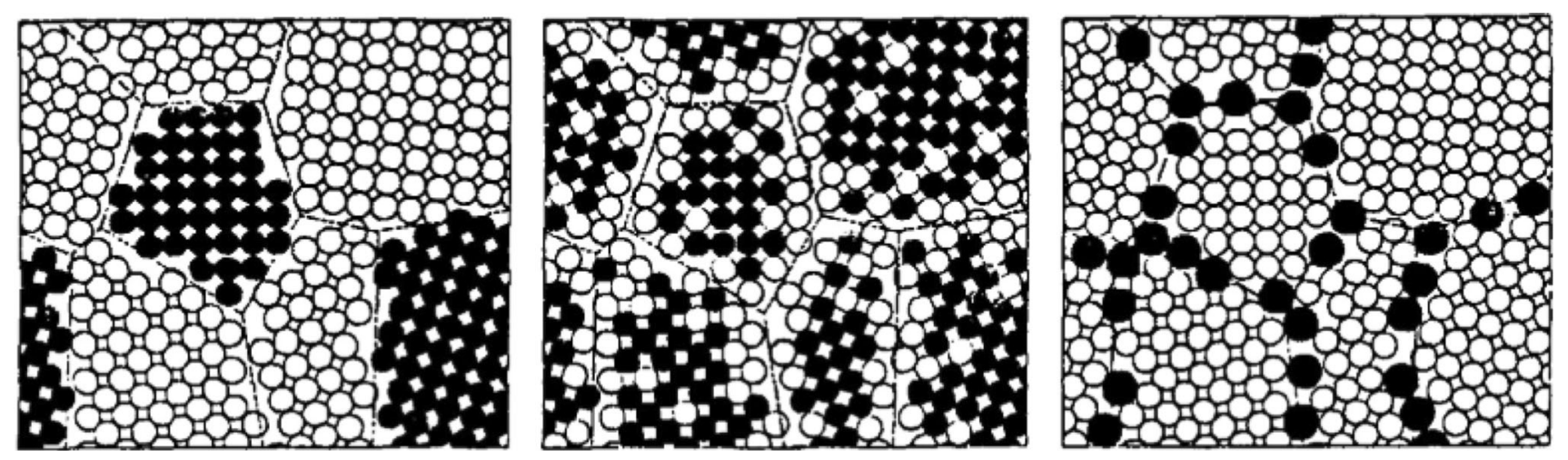

Fig. 5-Representation of three distinct NC alloy configurations. The left and center images illustrate microstructures suggested by Gleiter. The right presents the novel concept of segregated solutes decorating a grain boundary. Reprinted from Ref. [75] with permission from Elsevier.

homogeneously to grain boundaries, and no excess solute existed in the form of precipitated phases or impurities.

In experimental studies, the assumption of all solute residing at boundaries is challenged by the inability of SPD processing to force all of the solute into an interface, though this to a degree is controllable by post-process annealing. ${ }^{[83]}$ However, once the thermodynamically necessary amount of solute has settled into the grain boundaries the remaining solutes are free to pursue other kinetic mechanisms for stabilization. A model by $\mathrm{Li}$ et al. ${ }^{[84]}$ presents a plausible balance between the drag force in kinetic models and the reduced driving force for grain growth based on stabilizing solute segregation. Using traditional thin-film approaches and mechanical milling pathways, researchers have exploited these findings to engineer "thermally stable" nanocrystalline systems that employ both thermodynamic and kinetic pathways to minimize the grain boundary energy and/or kinetically pin the boundaries with solutes or nanoclusters ${ }^{[85-99]}$ or a harder grain boundary phase. ${ }^{[83,100,101]}$ These all serve to increase the alloy's stability against grain growth at high homologous temperatures $\left(>0.5 T / T_{\mathrm{m}}\right)$ or, in some cases, suppress detrimental phase transformations, ${ }^{[102]}$ besides also imparting many other exceptional mechanical properties. ${ }^{[103-107]}$ A recent perspective piece by Spearot et al. ${ }^{[108]}$ specifically speaks to the mechanical properties of stabilized fcc metals, and some unexplored future research needs and opportunities. Some intriguing ideas presented include understanding the role of chemistry on the transition between dislocation-based 
plasticity and grain boundary-mediated plasticity in thermally stable alloys, along with appropriate constitutive models that also account for this transition.

The knowledge in this important space is continuously evolving, ${ }^{[109]}$ and the community venturing into such work is rapidly expanding, so no further discussion will be lent here other than to say that any method that seeks to harness Gleiter's vision (and Turnbull's “energize and quench" philosophy") for nanocrystalline materials will necessitate a thorough understanding of the thermodynamic and tacitly linked kinetic theory to retain the beneficial nanostructures. More so, the exploitation of present materials processing methods (in fact, most only a small technological step from the thin-film and cluster-consolidation approaches used and suggested by Gleiter and other fast-follower ${ }^{[21-23]}$, combined with advanced characterization and computational theory, will allow discoveries in thermal stabilization of nanocrystalline grains to continue.

\section{A. Potential Openings for Study}

1. The vast majority of thermally stable materials are created via predicted solute segregation for thermodynamic energy reduction and, depending on the fabrication method, additional contributions to kinetic stability through excess impurities (e.g., oxides, nitrides, carbides), solutes, precipitated phases, and amorphous complexions. The contributions of both solute segregation and kinetic stabilizers are essential for a more complete understanding of stabilization of the grain size, and maximization of strength property improvements. They cannot be considered independently, but work on oxide-resistant noble metal alloys fabricated by pristine processing methods that limit impurities is certainly an excellent starting point to understanding the independent role of solute segregation on thermal stability. ${ }^{[98,105]}$

2. Thin-film processing ${ }^{[10]}$ and mechanical milling have both offered the energy needed to force solute atoms into non-equilibrium supersaturated states at grain boundaries and triple-junctions, with the latter approach often needing an anneal and quench to segregate solutes to the interface. While severe plastic deformation methods such as HPT and ECAE are being used to densify thermally stable alloy powders produced by milling, studies on the ability of these and other bulk severe plastic deformation methods to generate thermally stable nanocrystalline grains via microstructural refinement are currently lacking. Under extremely large plastic strains, high pressures, and the right thermal processing conditions (perhaps cryogenic), the unique non-equilibrium boundaries engendered by SPD may provide a pathway to similar "bulk" thermally stable alloy systems, with the added potential for reduction in impurities compared to milling methods (if indeed, we do not want impurities).
3. The deformation mechanisms and mechanical properties of thermally stable alloys are only just being uncovered, and it is critical to continue explorations of the stability of the stable nanocrystalline grains under mechanical loading environments, such as wear, ${ }^{[105,111]}$ fatigue ${ }^{[61]}$ creep $^{[106]}$ high-strain rates, ${ }^{[107]}$ irradiation, ${ }^{[112,113]}$ and high pressures, and to critically compare the findings with the more traditionally processed NC materials.

\section{ON THE ROLE OF "DIRT" ON GRAIN BOUNDARY STABILIZATION}

Gleiter's bitter colleague referred to the proposed volume of defects as "dirt." But in traditional usage, dirt is considered impure and undesirable. We frequently refer to terms such as "commercial purity" and ask for the number of 9's, but intrinsically, we know that the materials we work with do not solely consist of elemental atoms. In the field of "Ultra-High-Purity Base Metals" (UHPM), ${ }^{[14]}$ it is recognized that trace impurities can have large effects on various properties ${ }^{[115]}$ and, in general ultrapure metals have shown higher ductility, lower recrystallization temperatures and lower strength and hardness values compared to the same commercially pure metals. ${ }^{[116,117]}$ From the beginning, ${ }^{[11,46]}$ in the majority of materials processed by mechanical milling or severe plastic deformation methods, there have been a multitude of impurities, whether introduced, in the case of the former, or unavoidably maintained in the starting material of the latter. ${ }^{[22]}$ For mechanical milling, impurities are acquired from the milling media (often Fe or WC), the milling environment (air, nitrogen), and process control agents (often C-based organics), if used. For bulk metal processing, impurities can be remnants from the extraction or refinement, resulting in imprecise chemistry of the processed metal. It should be clear that the vast majority of deformation-processed nanocrystalline metals have had some level of unavoidable "dirt."§

\footnotetext{
${ }^{\S}$ Kudos to those that chose to take the thin-film synthesis pathway to nanocrystalline metals. ${ }^{[110]}$ Their methods are largely clean and precise compared to severe plastic deformation, but also come with some limitations (e.g., the "thin" part) that will not be addressed here.
}

These impurities, when in solute, cluster or precipitate forms, are now known to provide an additional kinetic component to nanocrystalline grain size stabilization by exerting a pinning force on the boundary. ${ }^{[118-120]}$ In his seminal 1948 work, Smith ${ }^{[121]}$ investigated soap froth ${ }^{\S \S}$

\footnotetext{
${ }^{\$ \S}$ I would not have been clever enough to do this experiment, but if I had, I would have chosen beer based on Prof. David Srolovitz's brilliant theoretical work. ${ }^{[281]}$ A 2007 Scientific American article stated that "they may be able to engineer stronger materials - or minimize the foam on a glass of beer. "This formula," Srolovitz says, "basically tells you how every single bubble in the head of beer is going to change." ${ }^{[282]}$
} 
to glean conditions under which the bubble growth would be stabilized through anchoring by rigid, insoluble inclusions. More particles would pin boundaries with very large curvatures. Zener provided him with a semi-quantitative relationship that has come to be known as "Zener pinning",[122].

$$
R_{\mathrm{p}}=\beta \cdot \frac{r}{f_{\mathrm{v}}^{m}}
$$

where $R_{\mathrm{p}}$ is the limiting grain radius, $r$ is the spherical inclusion diameter and $f_{\mathrm{v}}^{m}$ is the inclusion volume fraction. The volume fraction exponent, $m$, and the pinning factor, $\beta$, were proposed by Smith to be 1 and $4 /$ 3 , respectively, and $m$ has been found to be closer to $2 / 3$ by more recent simulations and experiments. ${ }^{[122]}$ The impurities, clusters, and precipitates introduced during severe plastic deformation approaches also contribute to solute drag theory. ${ }^{[82]}$ The work by Michels et al. expanded on the well-known Burke model for solute drag, ${ }^{[123]}$ which did not consider the effect of grain size on the drag force. Michel et al. importantly modified the Burke model to include the contributions of the larger number of solutes that would reside on a grain boundary in a nanocrystalline material. ${ }^{[124]}$ These mechanisms are clearly at play when materials are processed in ways such as mechanical milling or cryomilling ${ }^{[23]}$ where reactions with the milling container, media, and processed materials with residual organic process control agents, oxygen and in the case of cryomilling, nitrogen, can result in the formation of nitrides, carbides, and oxides that kinetically suppress grain growth. They may also play a lesser role in SPD, depending on the starting purity of the metal and the specific strain, strain path, pressure and temperature, and the resulting defect density, dislocation core configurations, and grain size. ${ }^{[67,125]}$

Thin-film work on nanocrystalline materials has provided us with insights into subtle impurity effects. Zhang et al. " showed that in highly pure thin-film $\mathrm{Cu}$

\footnotetext{
"Prof. Julia Weertman was a pioneer in the study of nanocrystalline materials. In her 2003 Von Hippel award lecture, titled "The Pursuit of the Small: From Grain-Boundary Cavities to Nanocrystalline Metals,",[169] she addressed synthesis challenges ("Synthesis methods must be radically improved, so that we are not making "femto-grams in a fortnight" [a quote attributed to Jim Williams of The Ohio State University]), the need to understand the deformation mechanisms at various grain sizes and in more materials, and the drive for a better understanding of the importance of internal structural features, high internal strains, and defects. Weertman was a trailblazer in so many ways, but her incomparable impact continues to resonate in the most recent scientific pursuits of the bulk $\mathrm{NC}$ and UFG materials community.
}

(99.999 vs $99.96 \mathrm{wt}$ pct), the impurities served to limit the rate of nanocrystalline grain growth. ${ }^{[120]}$ Building on this, Gianola et al. investigated the stability of thin-film Al with varying oxygen concentrations (3 to 10 at. pct) and demonstrated the immobilization of $\mathrm{NC}$ grain boundaries during applied stress. ${ }^{[126]}$ Subsequently, he and co-workers used in-situ electron microscopy and 3D atom probe to explore the mechanics and kinetics of the oxygen stabilization, and quantify the excess boundary solute clusters needed for stabilization. ${ }^{[127]}$

On the powder metallurgy side of things, cryomilling studies on the effects of $\mathrm{O}$ and $\mathrm{N}$ in $\mathrm{Cu}$ showed that in the as-cryomilled condition, the $\mathrm{NC}(\sim 45 \mathrm{~nm}$ grain size $)$ "alloy" had a composition including 0.512 pet $\mathrm{O}$, 0.26 pet $\mathrm{N}, 0.027$ pet $\mathrm{C}, 0.064$ pet $\mathrm{Fe},<0.0005$ pct $\mathrm{Al}$, and 0.0094 pet $\mathrm{Cr}$ (all in wt pet). ${ }^{[128]}$ The $\mathrm{O}$ and $\mathrm{N}$ contents in the starting powder were 0.45 and 0.004 wt pct, respectively, indicating the pick-up of both elements during cryomilling. This report also verified the formation of $\mathrm{CuO}$ while leaving the samples at ambient temperatures in air, which later decomposed into $\mathrm{Cu}_{2} \mathrm{O}$ at elevated temperatures. Follow-on studies have indicated enhanced stabilization through the uncontrolled or controlled formation of grain boundary oxides. ${ }^{[94,129-137]}$

To study the effect of such impurities and solutes on the stability against grain growth during high-temperature deformation, Lin et al. ${ }^{[138]}$ studied a 5083 Al bulk alloy produced via cryomilling and hot-isostatic pressing consolidation (HIP) with $\sim 244 \mathrm{~nm}$ grain sizes. After these processing steps, they discovered that the solutes and precipitates at the grain boundaries suppressed grain growth during annealing at $673 \mathrm{~K}$ for 5 hours ( $262 \mathrm{~nm}$ post-annealing); however, when heated the sample at the same temperature for 1 hour, then quickly extruded $(\mathrm{AR}=10$, true strain $\sim 2.30)$ and quenched it, the grains had grown to $\sim 647 \mathrm{~nm}$. This behavior was attributed to segregated solutes and precipitate particles pinning the grain boundaries and providing resistance to grain boundary rotation during static annealing, and while the particles and precipitates still remained somewhat active during the high-temperature extrusion, the superimposed stress was somewhat able to overcome their pinning potency, therefore enabling some grain boundary rotation and grain growth. ${ }^{\text {"थ }}$

\footnotetext{
"This 2014 Metallurgical and Materials Transactions A paper, titled "Stress-Induced Grain Growth in an Ultra-Fine Grained Al Alloy," [138] was presented by Prof. Lavernia for the 2013 Edward DeMille Campbell Memorial Lecture. Prof. Lavernia has been a tremendous force in the field of bulk nanostructured materials by severe plastic deformation, but especially with his contributions to low temperature, cryomilling pathways to nanocrystalline materials.
}

With the knowledge that solutes or precipitates formed during SPD can provide grain boundary stabilization, some recent studies, such as those implementing a new SPD method known as surface mechanical grinding treatments (SMGT), come into question. ${ }^{[139]}$ This work suggests that refinement of the surface microstructures via the cryogenic (liquid nitrogen $\sim 77 \mathrm{~K}$ ) surface grinding of copper (99.97 wt pet) by a WC-Co spherical tip results in extremely fine grains $(<40 \mathrm{~nm})$ on the surface that demonstrate extreme thermal stability below this threshold grain size. ${ }^{[139]}$ TEM energy-dispersive spectroscopy (EDS) and electron energy loss (EELS) were reported to detect no "obvious" carbon or oxygen impurities deeper than $500 \mathrm{~nm}$ from the surface as a result of the limited 


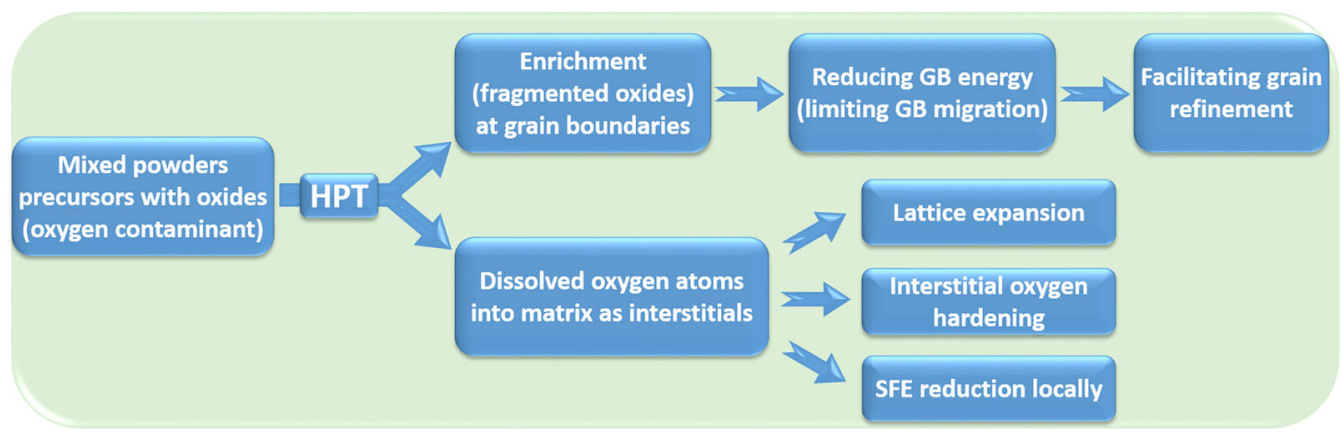

Fig. 6-Illustration of oxygen effects in nanocrystalline alloys produced by milling + high-pressure torsion consolidation. Reprinted from Ref. [140] with permission from Elsevier.

diffusion at cryogenic temperatures, and authors did not consider the data from the top $1 \mu \mathrm{m}$ in their analyses. Despite these surprising findings that contradict literature reports of unstable grain growth in pure $\mathrm{Cu},{ }^{[72,73,120]}$ some key details are absent to assess the validity of the work. Firstly, the $0.03 \mathrm{wt}$ pct that make up the chemical remainder of the $\mathrm{Cu}$ that was used and measurements of increased $\mathrm{N}$ from the cryogenic liquid are not given. Secondly, the supplement indeed shows $<5$ at. pct trace oxygen throughout the depth of the sample, but not the chemical nature (i.e., was it elemental or in $\mathrm{CuO}$ ?) nor the location of the oxygen. Thirdly, the grain boundary energies are only compared to "bulk" severe plastic deformation approaches that do not subject the nanocrystalline region to potential frictionally produced surface impurities. Lastly, the stabilization is only reported based on thermodynamic considerations, and kinetic factors are not discussed (based on the author's assessment of no obvious impurities).

The ability to precisely control impurity-defect interactions during the SPD generation of nanostructured materials and to understand their effects on the resulting properties are only recently being explored, such as in the work of Guo et al. ${ }^{[140]}$ This comprehensive study investigated the role of oxygen in both mechanically alloyed ( 0.780 at. pct $\mathrm{O}$ ) and high-pressure torsion-processed (0.047 at. pct $\mathrm{O}) \mathrm{CuFe}$ alloys and demonstrated the diverse effects of the dissolved oxygen on the grain boundary energy, lattice strain, interstitial hardening, and local SFE reduction, as shown in Figure 6.

Let's take a step back and mention that Gleiter suggested that fcc materials were not processible to nanocrystalline grain sizes due to being "too-soft" and therefore cold-welding into large mm-scale particles. ${ }^{[7]}$ Witken and Lavernia ${ }^{[23]}$ and Lavernia et al., ${ }^{[11]}$ among many others, subsequently have in some part proven this conjecture wrong and address the issue of impurities succinctly and poetically ${ }^{[23]}$.

If one's ambition is to interrogate the fundamental properties of an elemental material in a particular lattice system, e.g., face-centered cubic, as its grain size is reduced below $100 \mathrm{~nm}$, then the presence of contamination, whether metal particles derived from milling debris, or secondary phases and particles from process control agents, clearly compromises the integrity of the material. On the other hand, if one is trying to produce an engineering material with a particular combination of strength, density, and creep resistance, then the addition of secondary particles may be desirable if not indeed practical and necessary.

This leads into a concern, combined with an opportunity for growth in the nanostructured metals community. We certainly cannot go the way suggested by the UHPM community ${ }^{[114]}$ who conclude that "the inherent properties of metals cannot be predicted based on the knowledge of traditional metallurgy [...] the starting point of fundamental research for discovering the inherent properties should be the ultra-purification of metals." Philosophically, this mirrors the disparity between Gleiter (who wanted defects) and solid-state physicists (who wanted perfection). The true value to the engineering community requires the exploitation of emerging knowledge on the role of impurity-defect interactions for the fabrication of materials with ever-increasing beneficial properties.

\section{A. Potential Openings for Study}

1. Impurities are unavoidable, but it is a mandate that we thoroughly address their presence and role in nanocrystalline grain refinement, stability, and observed properties under thermal and mechanical loading conditions. In this regard, the emerging high-resolution microscopy (e.g., high-angle annular dark-field scanning transmission microscopy (HAADF-STEM), transmission Kikuchi diffraction (TKD) analysis), and microanalysis techniques (e.g., electron energy loss spectroscopy (EELS), atom probe tomography (APT)) are critical. ${ }^{[64,69,142-145]}$ When correlated with synchrotron/ beamline studies, these methods may provide the best pathway to new discoveries. More so, while the majority of studies have focused on pure metals, ${ }^{[146-148]}$ the role of impurity solutes is much less explored. In parallel, simulations should be increasingly expanded to account for the role of impurity solutes. ${ }^{[66,149,150]}$

2. Thermal stability studies are most often done via microstructural analyses pre- and post-annealing. Similarly, stress-induced grain growth studies are often been done at ambient temperatures, and again, investigated pre- and post-loading. For a 
true understanding of thermal stability, these tests must be done in concert and observed and measured with any number of in-situ loading/heating/imaging techniques. Of specific interests are studies that probe the role of disconnection- and disclination-mediated plasticity mechanisms at elevated temperatures, ${ }^{[151,152]}$ specifically in alloys engineered for thermodynamic or kinetic stability. A number of theories and simulations point to the critical role of disconnections in strain-induced environments where, in the absence of dislocation-controlled plasticity, collective grain boundary mechanisms determine grain boundary mobility. ${ }^{[153-155]}$ In parallel with advances in theory and simulation, in-situ microscopy studies ${ }^{[64,147,156,157]}$ at ambient and elevated temperatures will reveal the fundamental disconnection and disclination deformation physics associated with alloys processed and engineered for thermally stability. These would be valuable, not just for knowledge of the retention of grain size in applications, but critically, to appropriately model ${ }^{[158]}$ and to assess the stability of the microstructures formed during elevated temperatures SPD processing, but also during the thermomechanical manufacturing processing conditions needed to fabricate end products.

3. The vision of "grain boundary segregation engineering" presented by Raabe et al. ${ }^{[159]}$ has yet to be fully exploited for the processing of bulk nanostructured metals via severe plastic deformation. The work by Guo et al. to study the specific effects of oxygen and oxides during SPD processing presents an excellent study to build from in this regard. ${ }^{[140]}$ This is an entirely separate enterprise from the aforementioned thermodynamic approaches that seek to lower the grain boundary energy, but given the implicit role of thermodynamics in the formation and segregation of oxygen and oxides, the thermodynamics and kinetics do go hand-in-hand and therefore must be addressed.

4. On second thought, maybe the UHPM community is on to something. By studying the effects of trace amounts of in solute form, or perhaps solute clusters, in an otherwise atomically clean lattice, the true physics of segregation and deformation during SPD processes could be discerned. But this endeavor would be best started computationally through advancements such as ab-initio first-principle and molecular dynamic simulations. ${ }^{[160]}$

\section{THE FINEST GRAIN SIZE PART 1: HOW LOW CAN YOU GO (THEORETICALLY)?}

During studies on the limits of grain refinement to the nanoscale, there have been two questions that have driven the community:

1. What is the smallest grain size that can be generated through severe plastic deformation?

2. What grain size is the "strongest"? $[161,162]$
The smallest grain size achievable through deformation processing of a given material was not discussed by Gleiter. ${ }^{[7]}$ However, the ensuing studies to understand the grain size limit were, in part, driven by the desire for uncovering the physical mechanisms for observations of an inverse Hall-Petch slope in nanocrystalline materials below a critical grain size $\left(d_{\mathrm{c}}\right)$ regime. ${ }^{[62,163-165]}$

Starting with a look into the past, in $1963 \mathrm{Li}$ addressed the interacting effects of dislocations and grain boundaries, and their effects on the "Petch Slope." ${ }^{[166]}$ Soon after, Embury and Fisher ${ }^{[167]}$ reported an empirical relationship that modeled the mean distance between sub-structural barriers in highly drawn fine pearlite, thus presenting the concept of a minimal cell size that can support the storage of dislocations. These works, along with those developed by Armstrong et $a l .^{[18]}$ and others, were built with the supposition that the physical mechanism of strengthening was the pile-up of dislocations at a grain boundary. Nieh and Wadsworth $^{[168]}$ developed a simple model that assumed that a grain size exists wherein only one dislocation could be supported and under which the amorphous limit is reached. This grain size, $d_{c}$, would also be the size where the material would be the strongest. The spacing of two repulsive edge dislocations in a grain would be at equilibrium when the repulsive force was balanced by the applied force:

$$
L_{\mathrm{c}}=\frac{3 G b}{\pi(1-v) H},
$$

where $L_{\mathrm{c}}$ is the equilibrium distance between two edge dislocations, $G$ is the shear modulus, $b$ is the Burgers vector, $v$ is the Poisson's ratio, and $H$ is the hardness. If the grain size $d$ is smaller than $L_{\mathrm{c}}$, then it was suggested that dislocations could not pile-up in a grain. At a hardness of $1.5 \mathrm{GPa}$, Nieh and Wadsworth estimated the $L_{\mathrm{c}}$ for $\mathrm{Cu}$ to be $19.3 \mathrm{~nm}$, which phenomenologically agreed with the observations of $\mathrm{Cu}$ grains from a study (albeit fundamentally flawed due to reheating the same samples to produce larger grains ${ }^{[169]}$ ) by Chokshi et al. with grains from 8 to $16 \mathrm{~nm}$ showing an inverse Hall-Petch trend. ${ }^{[170]}$ Various follow-on studies have used this approximation, ${ }^{[62,171,172]}$ but with a variety of materials produced in a variety of ways. Arzt provided a similar treatment to that of Nieh and Wadsworth for a spectrum of mechanical properties as a function of grain size. ${ }^{[49]}$ His approximation for the smallest grain size before Hall-Petch breakdown was based on the assumption that for dislocation-based plasticity to occur, at least one dislocation loop would need to fit in a grain. ${ }^{[49]}$ These assumptions were in line with the work of Holt $^{[173]}$ and Holt and Staker ${ }^{[174]}$ from nearly three decades earlier. At a given shear stress, $\tau \approx G b / d$, where $\mathrm{G}$ is the shear modulus, $\mathrm{b}$ is the magnitude of the Burgers vector, and $d$ is the minimum grain size. From Arzt's approximation, the minimum grain size in $\mathrm{Cu}$ should be $50 \mathrm{~nm}$.

Shiøtz and Jacobsen with molecular dynamics simulations posited the softening in nanocrystalline materials below a threshold size to be a result of a transition from dislocation-mediated plasticity within the crystal to 
grain boundary dislocations. ${ }^{[175]}$ This proposition has been validated through simulations and experiments. ${ }^{[176-179]}$ Argon and Yip later developed a theory that balanced the plasticity rate mechanisms between grain boundary shear and dislocation plasticity and found that plastic resistance is maximum, in copper, at a grain size of $12.2 \mathrm{~nm}^{[162]}$ Another concept for the generation of nanocrystalline materials which has not yet been discussed is the intentional crystallization of amorphous solids. ${ }^{[180]}$ Sun and $\mathrm{Lu}$ presented an alternative pathway to prediction of the grain size based on extrapolation of isothermal thermodynamic data and theoretical considerations. ${ }^{[181]}$ Herein lies the rub; nearly any experimentally observed minimum grain size can "be in general agreement" to any of the theoretical models that have been developed. Just for the simple case of $\mathrm{Cu}$ presented here, a grain size as low as $8 \mathrm{~nm}$ has been reported, while the smallest possible grain size is predicted to be anywhere from $12.2 \mathrm{~nm}^{[162]}$ to $50 \mathrm{~nm} .{ }^{[49]}$ Of course, there are caveats, including that many of the early grain size measurements were made from diffraction methods such as the Williamson-Hall method ${ }^{[182]}$ or Scherrer's equation, ${ }^{[183]}$ but with the excellent microscopy tools available today, accurate statistical measurements are far less of an issue. Our current knowledge tells us that just because a dislocation is not seen in a grain does not mean it can't support dislocation activity (e.g., nucleating on one side and absorbing on the other in a small grain.) Indeed, dislocation activity has been seen in Pt grains as small as $6 \mathrm{~nm} \cdot{ }^{[179]}$

Our knowledge of fundamental physical models (with the associated mechanistic foundations) backing the limits of the Hall-Petch equation has continued to develop, and in some ways gets us around the fundamental deformation physics that influence plasticity and thus the spread in experimental data. ${ }^{[19,20,164,184]}$ Naik and Walley ${ }^{[185]}$ have reviewed the most recent understanding of such physical mechanisms for grain sizes below $1000 \mathrm{~nm}$, and their findings agree with the simulations of Shiøtz and Jacobsen ${ }^{[175]}$ on the softening role of grain boundary sliding at grain sizes less than $30 \mathrm{~nm}$. Incidentally, molecular dynamics simulations by Schäfer and Albe have shown that segregating solutes and their distribution in grain boundaries control the balance between grain boundary sliding and coupled grain boundary motion. ${ }^{[186]}$ More so, the distribution of these solutes determines the role of intergranular defects on plasticity. Further simulations and validating experiments add a nuanced opportunity to the previously discussed improvements in grain size stability offered by grain boundary solutes and the strengthening potential they offer. ${ }^{[187,188]}$ Returning to Naik and Walley, they also call into question the evidence in support of the inverse Hall-Petch mechanism, citing processing artifacts, stress-driven grain growth during testing (perhaps disconnection or disclination driven), and the observations from others that the Tabor analysis ${ }^{[189]}$ (HV $\left.(\mathrm{GPa})=\sigma_{\mathrm{ys}} / 3\right)$ may not fully hold true for nanocrystalline materials and that the actual denominator could lie anywhere between 2.3 to $3.7^{7^{190]}}$ or 4 to $8.6^{[191]}$
If these criticisms are indeed correct, perhaps a better pathway to predict the "ultimate strength in metals" is via an appropriate model of behavior on the other, softening side of the Hall-Petch plot.

Hahn et al..$^{[192]}$ and Wolf et al. ${ }^{[193]}$ attributed the inversion to the competition between grain boundary sliding and dislocation-dominated plasticity. On the hardening side, they used the Hall-Petch relation, and on the softening side, they assumed another linear model with fitting parameters based on the grain boundary width. Konstatinidis and Aifantis, ${ }^{[194]}$ and Zhang and Aifantis ${ }^{[195]}$ postulated the same balance, but treated the grain boundaries as a separate phase with a finite thickness that could be harder or softer than the grain interior. Zhang and Aifantis ${ }^{[195]}$ built on prior works by allowing the interfacial energy of the grain boundary to be defined as a function of the grain boundary yield stress. Thus, the yield behavior across a large span of grain sizes can be predicted by:

$$
\sigma_{\mathrm{YS}}=\sigma_{\mathrm{o}} \frac{k}{\sqrt{d}}+\frac{\gamma_{\mathrm{gb}}}{2 a d}
$$

where $\sigma_{\mathrm{ys}}$ is the yield strength, $\sigma_{\mathrm{o}}$ and $k_{\mathrm{y}}$ are the HallPetch constants, $\gamma_{\mathrm{gb}}$ is the interfacial energy, $a$ is the fraction of the grain size $(0<a<1)$, and $d$ is the grain size. Comparison with data from several nanocrystalline materials for $a=0.01$ proved to be a good fit. The equation for the minimum grain size for maximum strength $\left(d_{\mathrm{c}}\right)$ is given by:

$$
d_{\mathrm{c}}=\left(\frac{\gamma_{\mathrm{gb}}}{a k}\right)^{2} .
$$

With the fitting parameters and grain boundary energy they provide for $\mathrm{Cu}\left(k=124 \mathrm{kPa} \mathrm{m}^{1 / 2}, \alpha=0.01\right.$ and $\gamma_{\mathrm{gb}}=0.225 \mathrm{~N} / \mathrm{m}$ ), the minimum grain size for $\mathrm{Cu}$ is determined to be $\sim 32.9 \mathrm{~nm}$. While this model does appear to be effective for predicting nanocrystalline strength and the grain size where this is maximized, the presupposition of a separate grain boundary phase with a thickness that is some fraction of the grain size is not experimentally validated, nor does it provide the physical insight to fully understand the underlying deformation physics during softening as the grain size decreases.

Chandross and Argibay ${ }^{[196]}$ have developed a new scaling law that also predicts the "soft" side of the Hall-Petch plot, and by similarly observing the intersection with the linear Hall-Petch plot extrapolated from larger grain sizes, can estimate the smallest, strongest grain size. ${ }^{[197]}$ Importantly, the model does not need any new fitting parameters as with prior inverse Hall-Petch models. In their model, they provide a balance between the mechanical energy needed to deform the grain and the energy needed to "melt" the boundary. As the fraction of softened boundary decreases, the strength decreases. The energy needed to approximate the melting of the boundary is approximated as that of a high-angle grain boundary. With these assumptions, the maximum shear stress for a given metal can be predicted with the following equation $^{[196]}$ : 


$$
\tau_{\max }=\left(L \frac{\rho_{\mathrm{L}}}{M}\right)\left(1-\frac{T}{T_{\mathrm{M}}}\right)-\frac{k T}{b^{3}},
$$

where $\tau_{\max }$ is the maximum shear stress, $L$ is the activation energy per atom, ${ }^{[198]} \rho_{\mathrm{L}}$ is the density of the liquid phase at the melting temperature, $M$ is the atomic mass, $T$ is the temperature, $T_{\mathrm{M}}$ is the melting temperature, $k$ is Boltzmann's constant, and $b$ is the magnitude of the Burgers vector. Comparison of experimental data across a range of pure materials shows that this model provides a much better fit than previous crystal shear models $\left(\tau_{\max } \sim G / 30\right)^{[15]}$ and therefore may represent a better way of approximating the highest strength in a nanocrystalline material and the grain size needed to get there. Following the assumption that the amorphization energy is equivalent to the energy of a high-angle grain boundary, ${ }^{[199]}$ and a grain boundary width of $2 \mathrm{~b}$, Chandross and Argibay approximated the activation energy to be:

$$
\gamma_{\mathrm{HAGB}, \mathrm{calc}}=\left[L\left(\rho_{\mathrm{L}} / M\right)\right]\left[1-\left(T / T_{\mathrm{M}}\right)\right](2 b)
$$

If we crudely assuming a Schmid Law relationship where $\tau_{\max }=\tau_{\mathrm{CRSS}}$, then $\tau_{\max }=m \sigma_{y}$, where $\tau_{\max }$ is the shear stress treatment from Chandross and Argibay, $m$ is the Schmid factor $(\sim 1 / 3$ for fcc polycrystals and $1 / 2.75$ for bcc polycrystals) and $\sigma_{y s}$ is represented by the empirical Hall-Petch equation $\left(\sigma_{y}=\left(\sigma_{\mathrm{o}}+k d^{-1 / 2}\right)\right)$, the grain size at the highest shear strength $\left(d_{\min }\right)$ and the predicted shear strength at this grain size $\left(\tau_{\max }\right)$ can be estimated by:

$$
\begin{aligned}
\sqrt{d_{\min }} & =\frac{k_{\mathrm{HP}}}{\left(\frac{\left[\frac{\gamma_{\mathrm{HAGB}, \mathrm{cal}}}{2 b}-\frac{k T}{b^{3}}\right]}{m}\right)-\sigma_{\mathrm{o}}} \text { and } \\
\tau_{\max } & =\frac{\gamma_{\mathrm{HAGB}}}{2 b}-\frac{k T}{b^{3}}
\end{aligned}
$$

where $\sigma_{o}$ and $k_{\mathrm{HP}}$ are the experimentally derived Hall-Petch constants for a specific metal, and $\gamma_{\text {HAGB,calc }}$ is obtained from simulations ${ }^{[200]}$ (in the case of Chandross and Arigbay) or classic groove experiments. ${ }^{[201]}$ To approximate the minimum grain size for nanocrystalline $\mathrm{Cu}$, we will use the Hall-Petch constants from $^{[19]}\left(\sigma_{\mathrm{o}}=40 \mathrm{MPa}\right.$, and $\left.k_{\mathrm{HP}}=110 \mathrm{MPa} \mu \mathrm{m}^{1 / 2}\right)$, a Burgers vector magnitude of $b=0.26 \mathrm{~nm}$, a Schmid factor of $m=1 / 3$ for fcc $\mathrm{Cu}$, and a high-angle grain boundary energy of $\gamma_{\text {HAGB,calc }}=0.07 \mathrm{~J} / \mathrm{m}^{2}$ (from molecular dynamic calculations for $\mathrm{Cu}$ with a $200 \mathrm{~nm}$ grain size fabricated by ARB). ${ }^{[202]}$ The resulting $d_{\min }=17.9 \mathrm{~nm}$, the $\tau_{\max }=1.11 \mathrm{GPa}$, and via MacKenzie's crystal shear model $\left(\tau_{\max }=G / 30\right)$, with $G=45 \mathrm{GPa}, \tau_{\max }=1.5 \mathrm{GPa}$. These values appear to be overestimates when compared with experimentally determined maximum shear strengths from rotational diamond anvil cell studies $(\sim 100$ to $500 \mathrm{MPa}),{ }^{[203]}$ but the smallest predicted grain size of $17.9 \mathrm{~nm}$, and the steady-state experimentally observed values from high-pressure torsion $(\sim 35 \mathrm{~nm}),{ }^{[204]}$ by cryomilling with no exposure to the liquid $(\sim 23 \mathrm{~nm})^{[205]}$ and by cryomilling with exposure to the liquid nitrogen $(\sim 24 \mathrm{~nm})^{[206]}$ could be said to "be in general agreement." So where does this bring us in terms of estimating the smallest grain size and its role on strengthening? One thing we can certainly say is that, as Gleiter proposed, the properties of the grain boundary play an increasingly important role on deformation and strengthening in the nanocrystalline grain size regime, though perhaps not due to the defect structures he originally proposed. This leads to the need to critically understand the grain boundary structure and properties in not just the pure state, but in the presence of stabilizing solutes impurities or precipitates to fully know when and how a material may begin to soften. More so, we need to have a better understanding of how, as grains get smaller, they become both sources and sinks of the partial dislocations that control mechanical behavior at the macroscale.

\section{A. Potential Openings for Study}

1. With our ability to calculate electronic properties and interfacial boundary energies by density functional theory and other simulation approaches, ${ }^{[186,200,207]}$ the connections between the interatomic bond energy ( $\sim$ heat of fusion) and the strength of a nanocrystalline material may be unpacked for a vast number of systems, which represents a dual scientific and technological opportunity.

2. Nearly any study can correlate their minimum grain size with any number of theoretical limits and models. It is critically important that researchers consider explicit factors that could affect the validity of their observations. These include the effects of processing conditions, impurities, and grain boundary microstructure and mobility physics. This level of care has not traditionally been addressed by the severe plastic deformation community.

3. The Chandross and Argibay model tells us that grain boundaries should be softer than the lattice. Thus, the nature of the grain boundary, i.e., the microstructure and properties, must be understood, and controlled through emerging grain boundary engineering strategies such as "grain boundary segregation engineering," "complexions," or interstitial boundary effects. ${ }^{[140,159,208]}$ In particular, the high-volume fraction of grain boundaries in severe plastic deformation-processed materials may provide experimental data for the high-angle grain boundary energies needed for this particular model.

4. To this point, all models have ignored the physical fact that below a certain grain size, the grain boundary becomes the source and sink for dislocations. Further, partial, rather than full dislocations are emitted from grain boundaries. A model that can predict the change in dislocation dynamics at nanocrystalline grain sizes would be a very powerful tool. 


\section{THE FINEST GRAIN SIZE PART 2: HOW LOW CAN YOU GO (PRACTICALLY)?}

The theoretical models for minimum grain size presented in the prior section come with assumptions and simplifications that may not be fully grounded in the "real" behavior of nanocrystalline materials. Therefore, a return to the practical grain size limits of severe plastic deformation is in order. The initial observations of the grain size effects from mechanical milling provide some interesting observations. Experimentally, there appears to be a minimum steady-state grain size $\left(d_{\min }\right)$ that is characteristic for each metal. ${ }^{[21,209,210]}$ Next, $d_{\min }$ is observed to scale with melting temperature $\left(T_{\mathrm{m}}\right)^{[21,209]}$ and bulk modulus $(B) \cdot{ }^{[209]}$ Further, the $L_{\mathrm{c}}$ developed by Nieh and Wadsworth ${ }^{[168]}$ demonstrates a linear relationship with experimentally observed $d_{\min }$ values for a variety of pure metals processed by mechanical milling. And lastly, it was suggested that milling at lower temperatures results in smaller $d_{\min }{ }^{[21]}$

These observations led Mohamed to develop a dislocation-based model for predicting the minimum grain size achievable from mechanical milling. ${ }^{[211]}$ The model was built off of the phenomenological model suggested by Fecht ${ }^{[47]}$ and the suggestion by Eckert et al. ${ }^{[209]}$ that $d_{\min }$ would be governed by a balance between plastic deformation (stored dislocations) and thermal recovery mechanisms of a given metal (Turnbull's "energize and quench," once again). Mohamed cleverly observed that the steady-state $d_{\text {min }}$ observed with increasing milling time represented that the balance between dislocation multiplication/interactions (energizing) and dislocation rearrangement/annihilation (quenching) represented the same fundamental physical mechanisms for determining a minimum steady-state creep rate, minus the important distinction in operating temperatures $\left(>0.4 T_{\mathrm{m}}\right.$ for creep). However, in both cases, enhanced diffusion via pipe diffusion and enhanced vacancy concentrations are at play. Importantly, Mohamed recognized the role on impurities introduced from the milling operations and considered their effect on dislocation mobility. With a number of assumptions in place, the normalized minimum grain size was represented by:

$\frac{d_{\min }}{b}=A_{3}\left(e^{-\beta Q / 4 R T}\right)\left(D_{\mathrm{po}} G b^{2} / v_{\mathrm{o}} k T\right)^{.25}(\gamma / G b)^{0.5}(G / \sigma)^{1.25}$

where $A_{3}$ is a dimensionless constant, $Q$ is the self-diffusion activation energy, $\beta$ is a constant, $R$ is the gas constant, $T$ is the absolute temperature, $D_{\text {po }}$ is the diffusion coefficient, $b$ is the Burgers vector magnitude, $G$ is the shear modulus, $v_{\mathrm{O}}$ is the initial dislocation velocity, $k_{\mathrm{B}}$ is Boltzmann's constant, $\gamma$ is the stacking fault energy (SFE) and $\sigma$ is the applied stress. Using Tabor's analysis (and assuming it's validity) $(H=3 \sigma)$, the equation can easily be modified to be a function of hardness. This model compactly showed that the minimum grain size from mechanical milling scales inversely with hardness, exponentially with the self-diffusion activation energy for recovery, and proportionally with SFE. ${ }^{[25]}$ This model was also shown ${ }^{[211]}$ to fit the experimental results of pure fcc and bcc metals studied by Koch, ${ }^{[21]}$ Fecht et al. ${ }^{[46]}$ Fecht ${ }^{[47]}$ and Eckert et al. ${ }^{[209]}$ very well, while also cleanly explaining the relationship between $d_{\min }$ and parameters such as $H, Q, T_{\mathrm{m}}, B$, milling $T, L_{\mathrm{c}}$, and SFE. Mohamed tested his model against the data for pure fcc and bcc materials processed by HPT, ${ }^{[212]}$ ECAE, ${ }^{[213]}$ and mechanically milled hcp metals $^{[214]}$ and found strong agreement. Lastly, the model was expanded to correlate the smallest grain size achievable with the lattice strain introduced by the mechanical milling; in this case, the $(G / \sigma)^{1.25}$ term is replaced by $(1 / \varepsilon)^{0.94}$ where $\varepsilon$ is the lattice strain. ${ }^{[215]}$

While tremendously useful, the model does have some limitations identified by Cao et al. ${ }^{[36]}$ Firstly, Edalati and Horita ${ }^{[216]}$ have shown clear relationships between the minimum grain size, the specific heat capacity and atomic bond energies that are not accounted for in Mohamed's models. The effects of processing temperature (either low or high) on the deformation physics of different materials class (e.g., low- vs. high-stacking fault energy) are not incorporated, so mechanisms such as twinning are not addressed. Next, the effects of processing conditions, such as temperature, rate and pressure have strong effects on the steady-state grain size. For example, in high-pressure torsion, the imposed high pressure serves to both introduce and accumulate a higher number of dislocations, while at the same time reducing recovery mechanisms by suppression of vacancy diffusion. In ECAE this might not happen to the same extent, and therefore the steady-state grain size is often much higher than observed for HPT.

With these limitations in mind, it's important to think about the relative contributions of processing parameters and identify which ones lead to the finest grain structures in SPD-processed materials. Pippan et al..$^{[217]}$ walked through this exercise with the end goal of having an ultrafine-grained materials with high-angle grain boundaries and studied the effects of processing and microstructural factors on the onset strain needed to maximize refinement in single- and multiphase materials. Factors investigated included applied strain, deformation temperature, alloying, strain path, and pressure. Of these, the temperature, alloying and mode of deformation (cyclic vs monotonic) were reported to have the most influence on attaining a steady-state grain size. With the construct of "energize and quench" in mind, lower temperatures and monotonic strains increase dislocation multiplication while at the same time low temperature and alloying minimize microstructural recovery. To summarize and generalize their findings, Figure 7 was given. ${ }^{[217]}$ It is by no means complete, with many of the complexities of microstructural evolution more fully addressed by Cao et al. ${ }^{[36]} \mathrm{In}$ particular, Pippan et al. presents an incomplete picture of the role of stacking fault energy. ${ }^{[35,218]}$ However, their findings do present an excellent heuristic picture of which processing factors matter the most for obtaining a saturated grain size. 


\begin{tabular}{lcc} 
& $\mathrm{d}$ at saturation & onset strain of saturation \\
\hline temperature & very high & very high \\
strain rate & medium & medium \\
strain path & high & medium \\
pressure & low-medium & low \\
alloying & very high & medium \\
precipitations & high & $?$ \\
crystal structure & low & medium \\
stacking fault energy & medium & $?$
\end{tabular}

Fig. 7-Effect of processing parameter on the onset strain for saturation and the steady-state grain size during severe plastic deformation. Reprinted from Ref. [217] with permission from John Wiley and Sons.

The last point to be addressed is the practical contributions of typical SPD-induced nanocrystalline grain structures to strengthening. Balasubramanian and Langdon ${ }^{[219] *}$

\footnotetext{
*In yet another foundational Metallurgical and Materials Transactions $A$ paper titled "The Strength-Grain Size Relationship in Ultrafine Grained Metals," Prof. Langdon sought to honor Prof. Li ${ }^{[74,166]}$ on this 90th birthday. Both have made seminal contributions to deformation mechanisms, grain refinement, strengthening and the role of grain boundaries. I have had the opportunity to interact with Prof. Langdon via our shared technical community and hope to be honoring him on his own $90^{\text {th }}$ birthday at some point
}

and Valiev ${ }^{[220]}$ both inferred that the typical values for hardness in materials processed by severe plastic deformation are harder than what is predicted by extrapolation of the Hall-Petch relation from coarsegrained materials. They observed that the contributions to strengthening were based on the presence of a large fraction of high-angle grain boundaries and non-equilibrium boundaries found in highly strained SPD materials. Another speculated contribution was through non-equilibrium segregation of solutes or precipitation at grain boundaries for grains less than $<100 \mathrm{~nm}$. Both groups speculated that the precipitates would cause solute drag and suppress grain boundary dislocation emission, but they did not discuss the role that these solutes would play on grain boundary mechanical properties, stabilization of the grain size, or propensity to suppress or enhance grain boundary-mediated plasticity. Also conjectured was that given the large plastic strain, a higher number of dislocations than would be geometrically necessary and would migrate to the grain boundaries, thereby increasing the grain boundary energy. The majority of these observations, while plausible, were inferred from TEM microstructural analyses, hardness and mechanical response and as a function of applied strain during processing. In-situ studies and simulation studies that fully validate these prepositions are still lacking.

\section{A. Potential Openings for Study}

1. Physical parameters such as the atomic binding energy and specific heat capacity are empirically tied to the minimum grain size achievable during deformation processing. ${ }^{[216]}$ The work by Chandross and Argibay ${ }^{[196]}$ provides another example of predicting the smallest grain size achievable with easily found material parameters (in this case, the heat of fusion). Both examples illustrate the utility of understanding grain refinement without the use of fitting parameters, but rather, through the use of easily found material and physical parameters connected to underlying deformation physics.

2. The models presented by Mohamed, ${ }^{[211-213,215]}$ while currently lacking many features that control grain refinement, are often underutilized in favor of the simple, theoretical models given in the prior section. Further developments and refinements to address the effects of processing conditions, phase transformations during processing, and newly emerging microstructural evolution pathways would be broadly applicable. In particular, the opportunity to use density functional theory to calculate parameters on which the minimum grain sizes are shown to depend, such as stacking fault energies, ${ }^{[221]}$ shear moduli, activation energies and others, can enable the expansion of such models beyond simple elemental system to more complex alloy systems where such parameters are currently not known.

3. Grain boundary orientation, microstructure, mobility, and properties are all speculated to contribute to the observed enhanced strength and mechanical response of SPD-processed materials; however, while experimental validation tools and accurate simulations of grain boundary features and mechanisms have been developed, they have yet to be sufficiently harnessed for SPD nanocrystalline materials development. The assumptions of grain boundary effects will be addressed, in part, in the following section.

\section{NON-EQUILIBRIUM AND EQUILIBRIUM GRAIN BOUNDARIES}

\section{A. Grain Boundaries in Severely Plastically Deformed Metals}

The disorder prescribed at the grain boundary of nanocrystalline material was stated by Gleiter to be atomically periodic in nature and fundamentally different from the parent crystal lattice. Further, the term "interphase" $[7,222]$ was frequently used to describe a non-equilibrium alloy phase in the strained lattice region of the grain boundary between crystals of two different elemental materials. In 1983, Valiev et al. ${ }^{[223]}$ similarly defined a "non-equilibrium" grain boundary as one that has trapped, extrinsic dislocations that are not necessary 
to accommodate misorientation across the lattice. The distortion caused by these dislocations raise the grain boundary energy. Though mentioned by many in the following years with little, if any proof, Huang et al. ${ }^{[224]}$ provided the first conclusive evidence of such boundaries in an SPD-processed material (repeatedly corrugated and straightened pure $\mathrm{Cu}$ ). Despite this finding, the study of grain boundaries in NC materials made by SPD has continued to focus fairly superficially on the speculated role of the high-angle grain boundaries, rather than detailed characterization of the interfaces at grain boundaries. One comprehensive review of grain boundary phenomena affecting ultrafine-grained and nanocrystalline materials processed by SPD is a report by Sauvage et al., ${ }^{[225]}$ who addressed the role of non-equilibrium high-angle grain boundaries, diffusion, and solute segregation during SPD processing, and then the role they play on deformation and strengthening. The fundamental findings from this paper are reported here.

On the subject of the existence of a high-volume fraction of non-equilibrium, high-angle grain boundaries, Sauvage et al. ${ }^{[225]}$ reported that using high-resolution TEM, lattice distortions have been observed that validate the high-energy nature of SPD-induced boundary interfaces, and two important observations were made for SPD-processed materials with ultrafine grain structures:

1. Non-equilibrium grain boundaries exist in UFG materials and they possess an increased free energy density, increased width, and high-densities of dislocations (full or partial, $\sim 1 \times 10^{9} / \mathrm{m}$ ) associated with the near boundary region and corresponding large residual microstrains

2. The structural width of non-equilibrium grain boundaries is well-below $10 \mathrm{~nm}$, and has been observed to be as small as $\sim 1.5$ to $2.0 \mathrm{~nm}$, which is at least twice as large as a relaxed high-angle grain boundary in annealed coarse-grained material.

Regarding solute segregation, Sauvage et al. ${ }^{[225]}$ stated that very few studies have been performed to validate this hypothesis and that atom-probe tomography studies have shown no more solutes in an SPD grain boundary as function of misorientation than other conventionally processed alloys. Solutes were stated to generate solid solution hardening, precipitates, and pin dislocations, but these also are not grain boundary-controlled mechanisms. All of these serve to improve the mechanical response, but not specifically through the presence of solutes at a grain boundary. Atom-probe tomography (APT) studies on Al-alloys do show solute segregation to planar defects that enrich the boundaries (up to 25 at. pct) in a thick (6 to $8 \mathrm{~nm}$ ) layer ${ }^{[226]}$ but: (1) the solutes are not distributed homogeneously on the boundary, and (2) the energy of the boundary is not reported, and it would be expected that, owing to their higher free volume, low-angle grain boundaries could accommodate more solutes. In the end analysis, Sauvage et al. ${ }^{[225]}$ suspected that the excess solutes at grain boundaries arrived there via the high volume of point defects and dislocation pipe diffusion rather than to energetically reduce the energy of the grain boundary. They also addressed the enhanced diffusion proposed for SPD materials, and in his review of radio-tracer studies showed the following hierarchy of diffusivities (from highest to lowest): non-equilibrium boundaries $>$ general high-angle boundaries $>$ highly defected twin boundaries $>$ low-angle grain boundaries, dislocation walls and single dislocations. The importance of diffusion is framed from the conditions during SPD; low homologous temperature conditions suppress recovery, which in turn affect the point defect generation, segregation of impurities, and atomic transport along interfaces, thus leading to other types of non-equilibrium grain boundaries that cannot be defined simply by misorientations and will individually have to be understood based on their defect content, relaxation times (kinetic parameters), chemical ordering/disordering, segregation, and compound formation (thermodynamic parameters) for a full understanding of their metastability. To close their review, Sauvage et al. ${ }^{[225]}$ proposed quantitative classifiers for SPD-induced non-equilibrium grain boundaries, suggesting the relative excess free energy compared to a relaxed high-energy grain boundary as a possibility, along with lattice distortion adjacent to the interface, the chemical width, or diffusion rate as other non-equilibrium state quantifiers. They suggest that grain boundary engineering via careful control of the grain boundary characteristics has yet to be done with SPD methods, wherein control of the energies, distributions, segregation and diffusion could provide for a wide breadth of beneficial properties.

To build on the report by Sauvage et al., ${ }^{[225]}$ Wilde and Divinski ${ }^{[227]}$ have presented another thorough review on the kinetic, thermodynamic and structural properties of interfaces in SPD materials, and their impact on the microstructural evolution and related mechanical properties. They presented concepts on grain boundary engineering through solute control, enhanced toughening via post-processing annealing, the generation of far-from-equilibrium phases and stabilizing solutes, correlation between grain boundary structures and grain boundary kinetic properties, and several other emerging topics that are required reading for anyone seeking to understand the nature of SPD-produced grain boundaries, but for conciseness, we will move on to some ideas that have received less treatment by the SPD community.

\section{B. Grain Boundary Phases in Pure Metals}

The high-shear processing conditions of SPD often result in a variety of phase transformations but the grain boundary phases induced in alloyed materials are less covered. ${ }^{[228]}$ Until recently, there has been no direct experimental evidence that such phases could even occur in an elemental metallic system. Meiners et al. ${ }^{[229,230]}$ have recently observed, for the first time, that grain boundary interfaces in pure metals may be composed of distinct crystallographic phases and undergo phase transformations at a variety of grain boundaries. ${ }^{[229]}$ The authors observed what they called "domino" and 
"pearl" co-existing phases in thin-film molecular beam epitaxy grown $\mathrm{Cu}$ on (0001) sapphire and annealed (673 K for 3 hours) with an end grain size of $100 \pm 50 \mu \mathrm{m}$. More so, the authors were able to use advanced machine-learning atomistic simulation approaches to show that the pearl phase is in a low-energy equilibrium state. The domino phase was simulated to be metastable and kinetically stabilized by a stress acting perpendicular to the grain boundary.

These results forecast the ability to predict, generate and control (stabilize) novel grain boundary phase structures in other pure metallic materials. Questions on the 3D nature of the grain boundary phase, the statistical distributions, and benefits such boundary phases may have over more conventionally observed grain boundaries need further exploration, but an interesting opportunity for the design of new materials may lie in the ability of severe plastic deformation approaches to stabilize the novel boundary polymorph phase domains. At $0 \mathrm{~K}$, the metastable domino phase was predicted to be stabilized with either 2 pct lateral strain, $\sim 5 \mathrm{GPa}$ of tensile stress or $440 \mathrm{MPa}$ of shear stress, and the conditions for the stability that allowed the physical observation at ambient temperatures are rationalized with corresponding simulations. ${ }^{[22]}$ Similarly, Aramford and Deng have performed molecular dynamics simulations to predict grain boundary transformations under mechanical loading. ${ }^{[231]}$ The core structures and disconnection energies in novel elemental grain boundary phases may consist of different properties, and thus allow control of boundary migrations and stabilization. Conditional on which metallic elements are used, the grain boundary type, the temperature and the loading conditions, the "severe" conditions supplied by typical nanocrystalline processing approaches may provide a pathway for novel property enhancement through the stabilization of novel elemental grain boundary phases, which, similar to complexions, may be a multitude in number. ${ }^{[232]}$ In his viewpoint article, Rabkin postulated the design of grain boundary polymorphs in aluminum that might block dislocation glide and simultaneously minimize electron scattering, thereby creating a "dream material" for electrical conductor wire. ${ }^{[230]} \mathrm{He}$ further speculated on the availability of processing methods to realize the full potential of this discovery; however, with severe plastic deformation methods here and mature, we may already be where we need to be.

\section{Controlling the Energy State of the Grain Boundary}

Gleiter and subsequent researchers have long speculated on the nature of the disorder in NC boundaries. For most of the last century, the boundary was thought be a thin, amorphous region; an idea that was dispelled as the years went on. However, as polycrystalline metals are reduced in grain size and the grain boundary volume increases, there is the tendency for the materials to behave in an amorphous manner, such as deformation by shear banding or grain boundary sliding/rotation, largely due to suppression of typically active dislocation-mediated plasticity effects. ${ }^{[164]}$ The high-energy boundary states in NC materials, whether by thin-film approaches or SPD, are mostly driven by the disorder at the interface, and relaxing these boundaries can result in beneficial modifications to the properties, such as a return in ductility mechanisms, increased damage tolerance, and toughening. Wilde and Divinski ${ }^{[22]}$ state that when done via annealing, that post-processing needs to be designed with an implicit understanding of the grain boundary state, and that short-time annealings are preferable. But the potential for retention of strength is questionable and, if possible, it would need to occur through the suppression of recovery, grain growth and precipitate coarsening reactions. More recently Balbus et al. ${ }^{[104]}$ have shown that femtosecond laser pulsing can be used to relax ("rejuvenate") nanocrystalline grain boundaries in Al-O and $\mathrm{Cu}-\mathrm{Zr}$ alloys, resulting in an 87 pct decrease in hardness with no grain growth. The rapid heating and cooling, along with the stress-state induced by the femtosecond laser below the ablation threshold largely circumvent the concerns presented by Wilde and Divinski. ${ }^{[227]}$ Usage of pulse laser energy is one of many ways that has been proposed to control the disorder at grain boundaries, ${ }^{[233-236]}$ and it offers an interesting pathway to tailoring properties in NC materials.

\section{Potential Openings for Study}

1. Emerging experimental tools and measurements are critical to have a more thorough understanding of grain boundary phenomena in SPD-processed NC and UFG materials. Recent advances in methods such as high-resolution transmission Kikuchi diffraction (HR-TKD) offer the possibility for unprecedented insights. ${ }^{[237-241]}$ Concurrently, our ability to simulate and measure the grain boundary properties and deformation physics is essential within the hierarchical framework of mechanisms needed to control property improvements.

2. In general, bulk annealing and quenching studies aimed at relaxing grain boundaries in SPD materials do so in a bulk manner. Femtosecond laser processing offers the ability to produce a heterogenous structure, not only as a function of depth, but in special patterns. The depth gradient is particularly interesting as it presents a clean approach to controlling gradient properties as a function of depth and maximizing the synergistic effects of hard and soft grains.

3. Given that strain- and pressure-induced non-equilibrium grain boundaries are generated by SPD, they may offer an excellent pathway to in-situ generate the stresses needed to stabilize novel metallic grain boundary phases.

\section{NOVEL DEFORMATION PROCESSING APPROACHES}

At this stage of the manuscript, stabilization mechanisms, the theoretical and practical minimum size achievable, and the nature and role of the grain 
boundaries in SPD-processed materials have been studied. But despite the major advances in alloying and deformation processing for NC and UFG metals, the majority of "new" SPD manufacturing methods are quite derivative of existing, well-explored approaches. Estrin and colleagues identified a number of outstanding scientific challenges but also a long list of severe plastic deformation methods, which functionally apply shear deformation in slightly varying ways. ${ }^{[38]}$ The sheer momentum of existing SPD methods has limited the transformative creativity needed to "energize and quench" in new ways. To move into what Michael Ashby might call the "white space"[242] for processing of $\mathrm{NC}$ and UFG metals, some examples that break the mold for processing are offered. These, in part, may overcome the "difficulties in specimen preparation" presented by Gleiter:

\section{A. Prospects for Nanomolding +}

To obtain the "bulk" materials needed for characterization and testing, the nanocrystalline research community has sought methods that create samples that are as large as possible while retaining the beneficial properties of the NC or UFG grains. These, along with the potential industrial applications, are what have made severe plastic deformation and large area thin-film approaches so appealing. But perhaps the interesting physics and discoveries lie at a much smaller scale. Liu et al. have given us a glimpse into the possibilities in a study on "nanomolding" of pure, crystalline Ag into long aspect ratio fibers by warm pressing coarse-grained material into a mold with pits of varying nanoscale diameters ranging from 5 to $320 \mathrm{~nm} \cdot{ }^{[243,244]}$ Incredibly, while pressing with a constant pressure, temperature and mold time, the nanopillars formed in the smaller diameter pits resulted in longer aspect ratios than for the larger diameter pits; the $5 \mathrm{~nm}$ diameter pillars had heights of $\sim 1700 \mathrm{~nm}$, representing some of the highest aspect ratio $(1 / d \sim 320)$ metallic rods ever extruded. Li et al. were able to duplicate this phenomenon in $\mathrm{Fe}, \mathrm{V}$, $\mathrm{Ni}$, other alloys and metallic glasses, demonstrating the universality of the approach for the processing of high aspect ratio nanopillars.

The conundrums that surround this feat are multifold. For example, how does a material with a grain size much larger than the pit diameter flow into the hole? If this were a nanocrystalline material, we'd likely ask if the plastic flow occurs via dislocation slip or grain boundary sliding. However, both are ruled out by the researchers since: (1) the grain size was much larger than the pit size and (2) the dimensions of the pit limit profuse dislocation activity. Enhanced diffusion $\left(1 / d^{2}\right.$ scaling, vs $1 / d$ scaling as seen in conventional diffusion, where $d$ is the diameter of the pit) was identified to be the operative mechanism through experiments and theory. The pressure gradient at the entrance of the pit creates vacancies in the lattice that hasten the mobility of $\mathrm{Ag}$ atoms (with some also traveling along the mold wall), and as the pit size decreases, the pressure increases, leading to enhanced vacancies and faster diffusion. Figure 8 presents a schematic of the "growth" of the $\mathrm{Ag}$ into the pit, and shows a $\sim 100 \mathrm{~nm}$ diameter nanorod (Figure 8(a)) with even smaller nanocrystalline grains at the base (Figure 8(d)), twinning at the tip (Figures 8(b) and (c)), and essentially a single crystal (in the Reference 110 orientation where atomic mobility is highest due to the low packing factor) along the length. At the beginning of the molding, the parent Ag grain (random) introduces the pressure gradient, and the resulting vacancies and dislocation activity facilitate the generation of nanocrystalline grains at the base of the pillar. The grain at the tip reorients until the preferred orientation for rapid diffusion (the lowest packing factor, in this case, ${ }^{[10]}$ ) is obtained, and then the single crystal grows by diffusion. The twinning at the tip represents a low-energy reorientation to maintain the Reference 110 directionality.

This begs the question of what this all has to do with nanocrystalline grains. To begin, this simple approach enables the fabrication of clean nanocrystalline grains at the base of the nanomolded pillar in a wide variety of metals and alloys at controlled temperatures (including cryogenic) and pressures. Additionally, with control of the grain orientation at entry, crystallographic texture effects on grain refinement could be investigated. Xu et al. have recently used this method to study the nucleation stress for an edge dislocation in $\mathrm{Al}$, and decouple it from the stress needed to drive dislocation propagation. ${ }^{[245]}$ This approach could easily provide a new path for the fabrication of nanocrystalline pillars of varying dimensions and geometries for nano- or micromechanical testing. The opportunity to bypass the cost and impurity risks of focused-ion beam preparation alone may make this method an important sample preparation approach for understanding the underlying deformation mechanisms of nanocrystalline materials.

\section{B. Prospects for Heterostructured Materials}

Gleiter postulated the potentially transformative nature of bulk nanocrystalline materials, but did not address the possibility of tailoring the properties via engineering their interaction with coarse-grained microstructures. This concept is fundamentally different from those posed by the rule-of-mixtures, where the constituent properties are more or less unchanged. Co-deforming a nanocrystalline material coherently connected with a coarse-grained region, either at a discrete boundary or along a gradient, involves new discoveries of the interlinked deformation phenomena. This emerging class of materials has been produced through a number of severe plastic deformation pathways that impart a severe deformation to the surface of a metal and through the generation or propagations of defects underneath, generate a gradient of grain sizes, with the top-most being the finest. Operations like surface mechanical attrition treatment (SMAT), ${ }^{[246-248]}$ surface mechanical gradient treatment (SMGT), ${ }^{[45]}$ rotationally accelerated shot peening (RASP), ${ }^{[249]}$ and Harmonic materials, ${ }^{[250,251]}$ are examples of deformation methods that can produce such microstructures. These new severe plastic deformation methods have been 


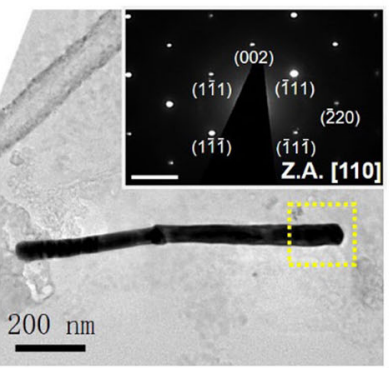

(a)

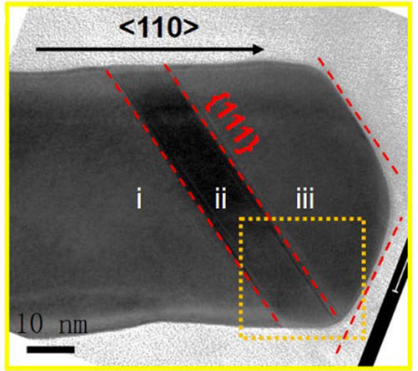

(b)

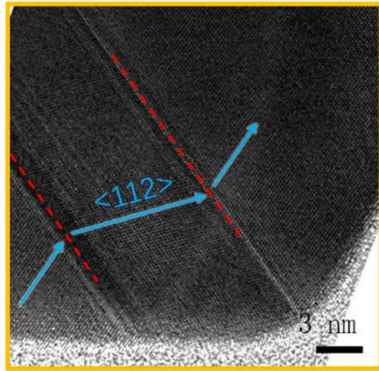

(c)

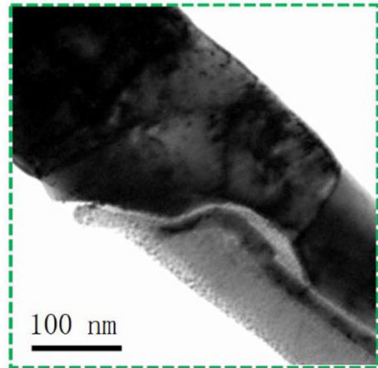

(d)

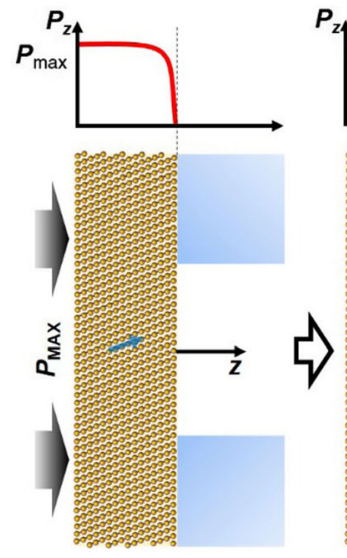

(e)

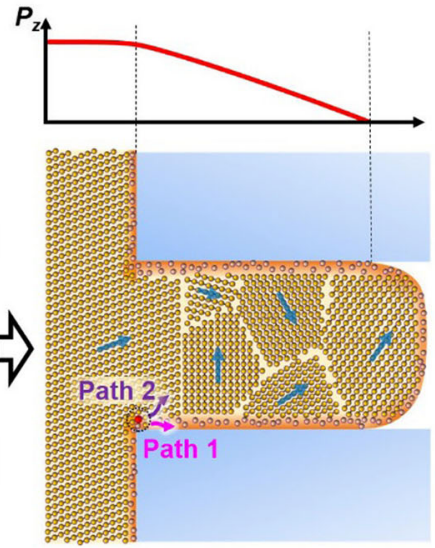

(f)
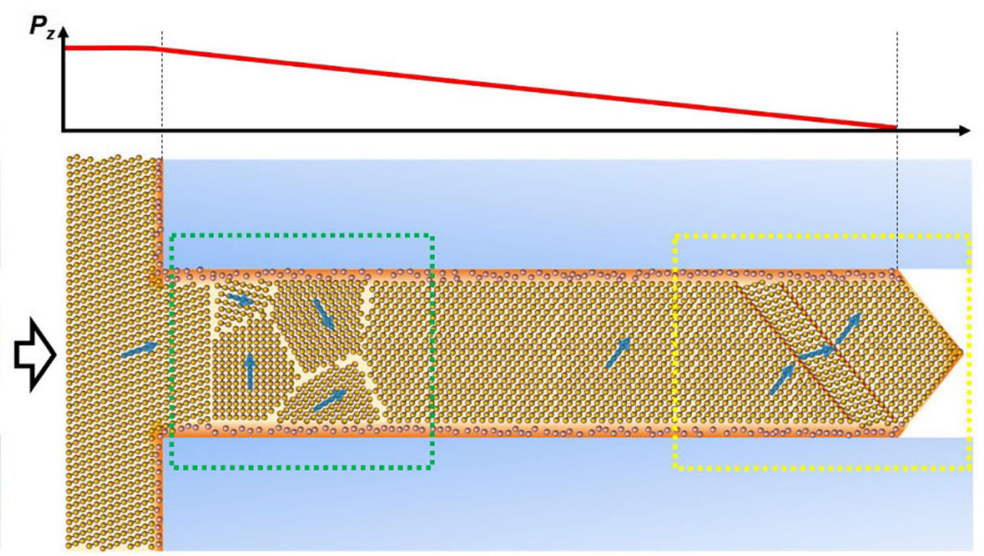

(g)

Fig. 8-Nanorod grain refinement and growth mechanism for nanomolded Ag. The sequence of processing allows the fabrication of deformation-induced nanocrystalline grains. (a) TEM bright field image of the Au nanorod, (b) and (c) close-up TEM images showing twinning at the tip, $(d)$ TEM showing multiple nanostructured grains at the root of the nanopillar, $(e)$ to $(g)$ schematic illustrating pressure profiles and atomistic deformation and nanopillar growth mechanisms, and (g) additionally illustrates the formation of nanocrystalline grains at the root, a long single crystal in the middle, and twins and faceted edges at the tip. Reprinted from Ref. [243] with permission from the American Physical Society.

bundled together under the term "Heterostructured Materials" as first proposed by $\mathrm{Wu}$ and $\mathrm{Zhu},{ }^{[252,253]}$ and includes bimodal, harmonic, lamella, gradient, domain-dispersed and hierarchical nanostructures. ${ }^{[254]}$ Figure 9 is illustrative of a lamellar heterostructured material. ${ }^{[252]}$ The primary observed benefit of this class of nanostructured materials is the excellent balance of strength and ductility as a result of the interlinked, non-homogeneous flow between the constituent microstructures. The specific critical microstructure that enables the enhanced mechanical response in heterogenous materials are nascent ${ }^{[57,255]}$ and will likely depend strongly on the material's crystal structure and composition, and processing method to achieve the end combination of nanocrystalline and coarse-grained features. Several reports and perspective pieces ${ }^{[252,254,256]}$ address the current state of heterostructured materials. The major focus of these papers is the underpinning mechanisms for ductility retention, such as the ability of heterogeneous microstructures to delocalize strain concentrations and distribute plastic flow and hardening, thus retaining the ability to work harden. ${ }^{[254]} \mathrm{A}$ more concrete, experimentally validated mechanism for enhanced ductility centers around hetero-deformation-induced (HDI) hardening, which results from the interaction between back stresses in soft domains and forward stresses in the hard domains. ${ }^{[256]}$ Overall, given the strong connecting thread between this new field of processing and traditional deformation processing of nanocrystalline materials, the tremendous opportunity for advances should be natural.**

**In the opinion of the author, a very similar transition has been made between the bulk metallic glass ${ }^{[283,284]}$ community and the high-entropy alloys community. ${ }^{[28-287]}$ The existing theory and experimental infrastructure provided the impetus for the shift in focus of a large scientific population in a very short time.

\section{Prospects for Solid Phase Processing}

An emerging class of processing techniques, coined "Solid Phase Processing" (SPP), has emerged as a mechanism for grain refinement and interface modulation in metals and alloys. The most well-known and well-studied SPP methods are friction stir welding (FSW) and friction stir processing (FSP) ${ }^{[257]}$ Other SPP methods may include cold-spray, ${ }^{[37,258-260]}$ friction extrusion, friction consolidation and shear-assisted processing and extrusion (ShAPE) methods ${ }^{[42,261-266]}$ and solid-state additive manufacturing. ${ }^{[267-270]}$ In the same way that heterostructured materials are somewhat artificially collected based on heterogenous 


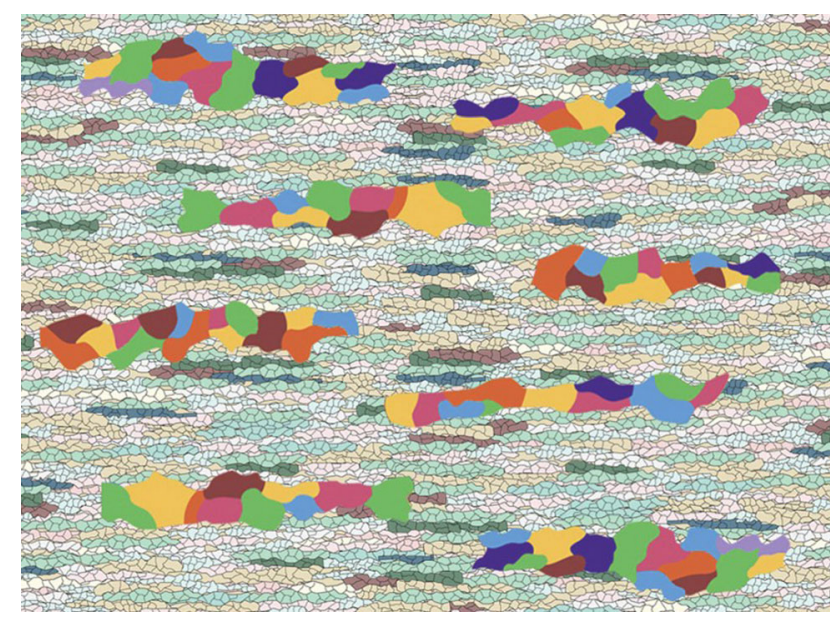

Fig. 9-Illustration of a lamellar heterostructured material composed of elongated, soft coarse grains embedded in nanocrystalline grains. Reprinted from Ref. [252] under the terms of the Creative Commons CC BY license.

microstructural features, SPP methods can be generally constrained with the following rubric:

1. No external heating is implemented. The highstrain, high-strain rate deformation under a confined environment drives defect generation which accommodates plastic flow.

2. Materials are typically incrementally shear processed and therefore only a small volume element undergoes deformation, as opposed to the bulk material plastic flow. This approach facilitates rapid heating and cooling of the region undergoing deformation.

3. The large shear strains over the small volume result in enhanced atomic diffusion and/or advection of mass. In combination with the rapid heating/cooling, this may result in microstructures very different from the equilibrium state.

Under typical SPP processing, the high number of defects generated by the intense shear results in a large degree of adiabatic heating and recovery and therefore dynamic recrystallization to grain sizes that range between 1 and $10 \mu \mathrm{m}$. Submersion in water, dry ice, or alcohol has been used to generate grain sizes of $\sim 100 \mathrm{~nm}$ in Al7075 alloy, ${ }^{[271]}$ 25 to $40 \mathrm{~nm}$ in $\mathrm{Al} 7050,{ }^{[272]} 174 \mathrm{~nm}$ in OFHC Cu${ }^{[273]}$ and $<100 \mathrm{~nm}$ in AZ61 Mg alloy. ${ }^{[274]}$ Analogously, cold-spray with mechanically milled powders has resulted in grain sizes in $\mathrm{Cu}$ (5 to $40 \mathrm{~nm}$ grain size $)^{[275]}$ and $\mathrm{Al} 5083$ (20 to $30 \mathrm{~nm}){ }^{[276]}$ Friction consolidation and ShAPE are versatile in that they can process both precursor powders or bulk ingot materials, but contrary to cold-spray, the high-shear and typical thermal recovery that is observed would annihilate any existing nanocrystalline grains in the mechanically milled powers. Yet, with bulk metals, SPP methods clearly generate the "energy" through shear-generated dislocation nucleation, and while grain sizes have historically been tamped by the concurrently ensuing recovery and grain growth, novel cooling and quenching approaches offer a clear pathway for their implementation for the fabrication of bulk nanocrystalline and ultrafine-grained metals.

\section{Prospects for Additive Manufacturing of Nanocrystalline Metals}

While this mechanism does not thematically fit in the conversations on grain refinement by severe plastic deformation, there are some intriguing- related opportunities. Additive manufacturing of metals and alloys typically starts in the liquid (melt) state and cools into an equilibrium (or at best metastable) state that has not yet been reported to be nanocrystalline. The emergence of nanophase separation and sintering in the solid phase provide a clear pathway for lower temperature laser additive manufacturing of nanocrystalline alloys with enhanced mechanical properties. ${ }^{[277,278]}$ However, the studies thus far have been limited to the $\mathrm{W}-\mathrm{Cr}$ and $\mathrm{CrNi}$ systems, ${ }^{[277,278]}$ thus efforts to explore the broadening alloy space for new powders are warranted.

Another opportunity could arise given the reports on the addition of nanoparticles to precisely control nucleation and stabilization of nanocrystalline regions during solidification. ${ }^{[279,280]}$ Demonstrations of this approach for a $\mathrm{Mg}$ alloy resulted in nanocrystalline grains with $\sim 14$ vol pct dispersed $\mathrm{SiC}$ nanoparticles with an ultra-high strength due to grain size and hard nanoparticle dispersions, and kinetically induced thermal stability. More recent work ${ }^{[279]}$ has shown that the same nanoparticle inclusion (WC in this case) strategy enables the slow-cooling (as low as furnace cooling, $\sim 4 \mathrm{~K} / \mathrm{s}$ ) of $\mathrm{Cu}$ into a blended ultrafine-grained $(1000 \mathrm{~nm})$ or nanocrystalline $(<100 \mathrm{~nm})$ grain structure. The finest average grain size achieved was $\sim 200 \mathrm{~nm}$ at $30 \mathrm{vol}$ pct $\mathrm{WC}$, regardless of cooling rate. The WC nanoparticles were shown to nucleate new grains from the melt and also to kinetically suppress the mobility of the grain boundaries as solidification progresses. In the $\mathrm{Cu}-\mathrm{WC}$ system, the structures were demonstrated to be very stable against grain growth up to $\sim 800{ }^{\circ} \mathrm{C}(\sim 75$ pet of the $T_{\mathrm{m}}$ for $\mathrm{Cu}$ ), with the stability being attributed to Zener pinning. More so, the mechanical properties were retained after annealing at $700{ }^{\circ} \mathrm{C}$ for 2 hours. The same effect was been shown for $\mathrm{Al}_{-} \mathrm{TiB}_{2}$ and $\mathrm{Zn}-\mathrm{WC}$, indicating the versatility of the approach for cooling rates less than $\sim 100 \mathrm{~K} / \mathrm{s}$. The cooling rates during conventional laser additive manufacturing can range from $\sim 20$ to $\sim 750 \mathrm{~K} / \mathrm{s}$, so the ability to make powder precursors of nanoparticle dispersion refined alloys could be an excellent pathway towards the processing of complex, $3 \mathrm{D}$ printed nanocrystalline component geometries not currently accessible through bulk severe plastic deformation methods.

\section{CONCLUDING THOUGHTS}

Despite being part history, part overview, and part exploratory science, it is hoped that this paper will provide a fraction of the inspiration that ensued from Gleiter's initial vision. His work is what the foundations of nanocrystalline metals are built on. Severe plastic 
deformation methods have proved to be a rich scientific field for making a host of nanocrystalline and ultrafine-grained metals with unprecedented properties, but for their utility to be maximized, they must be logically coupled with new discoveries, such as our ability to precisely control and maintain the grain size, engineer the disorder at the grain boundaries, and attain the smallest useful grain sizes that yield the best property improvements. These are just a few of the major advancements that have occurred in the last four decades, and with new methods of making nanocrystalline materials, ones that exploit the wealth of our ever-growing knowledge, more exciting scientific endeavors are on the horizon. At the same time, there is a lot that we do not understand, but in an era of amazing discoveries based on new simulations and tools for the advanced experimental study of materials at the length scales where the controlling mechanisms are operative, there are no excuses for us to not collaborate and find new ways to make, measure, and model new nanocrystalline materials that will someday prove beneficial to society.

\section{ACKNOWLEDGMENTS}

Metallurgical and Materials Transactions $A$ is, and will always be, a source of new fundamental metallurgical knowledge, and to write for the 50th Anniversary collection was beyond humbling. Within the nanocrystalline materials community, there are indeed many heroes who I have had the possibility to interact with and learn from. Special recognition goes to K. Ted Hartwig (Texas A\&M University), Yuntian Zhu (North Carolina State University/City University of Hong Kong), Enrique Lavernia (UC Davis/UC Irvine), Amiya Mukherjee (UC Davis), Carl Koch (North Carolina State University), Ruslan Valiev (Ufa State Aviation and Technical University), and Tresa Pollock (UC Santa Barbara) for mentoring and inspiration. Recognition also goes to my peers (at least temporally), Daniel Gianola (UC Santa Barbara), Tim Rupert (UC Irvine), Jason Trelewicz (Stony Brook University), Kiran Solanki (Arizona State University), and Brad Boyce (Sandia National Laboratory) for excellent single-malt whiskeys and stimulating conversations on the topics presented in that order. Lastly, I extend my gratitude to Herbert Gleiter for presenting such a disruptive idea and continuing to push the boundaries of what is possible with nanocrystalline materials. I further extend my thanks to him for the many stimulating discussions, but also my apologies for leaving the discussions on nanoglasses out of this work. Their time will come too. Funding for SNM comes, in part, from the US National Science Foundation CMMI under Grants 1554632, 1150986, 1463679, and 1663522 and, in part, as a part of a laboratory-directed research and development project under the solid phase processing science initiative (SPPSi) at the Department of Energy's Pacific Northwest National Laboratory.

\section{REFERENCES}

1. H. Gleiter: Proceedings of the 2nd Riso International Symposium on Metallurgy and Materials Science, H.L.N. Hansen, A. Horsewell, T. Leffers, ed., Roskilde, 1981, pp. 15-22.

2. J.M. Ziman: Principles of the Theory of Solids, Cambridge University Press, Cambridge, 1972

3. J.P. Hirth: Metall. Trans. A, 1985, vol. 16, pp. 2085-90.

4. A. Nordmann: Perspect. Sci., 2009, vol. 17, pp. 123-43.

5. H. Gleiter: Personal e-mail communication, March 27, 2020.

6. H.S. Kim, Y. Estrin, and M.B. Bush: Acta Mater., 2000, vol. 48, pp. 493-504.

7. H. Gleiter: Prog. Mater. Sci., 1989, vol. 33, pp. 223-315.

8. H. Gleiter: Acta Mater., 2000, vol. 48, pp. 1-29.

9. C. Suryanarayana: Int. Mater. Rev., 1995, vol. 40, pp. 41-63.

10. C. Suryanarayana: Bull. Mater. Sci., 1994, vol. 17, pp. 307-46.

11. C. Suryanarayana and C.C. Koch: Hyperfine Interact., 2000, vol. 130 , pp. 5-44

12. J. Frenkel: Z. Phys., 1926, vol. 37, pp. 572-609.

13. A. Kelly: Strong Solids, 2nd ed., Clarendon Press, Oxford, 1973.

14. N. Macmillan: J. Mater. Sci., 1972, vol. 7, pp. 239-54.

15. J.K. Mackenzie: Thesis, University of Bristol, UK, 1949

16. E.O. Hall: Yield Point Phenomena in Metals and Alloys, Plenum Press, New York, 1970.

17. N.J. Petch: J. Iron Steel Inst., 1953, vol. 174, pp. 25-28.

18. R.W. Armstrong, R.M. Fisher, and N. Louat: Philos. Mag., 1966, vol. 14, pp. 943-51.

19. Z.C. Cordero, B.E. Knight, and C.A. Schuh: Int. Mater. Rev., 2016, vol. 61, pp. 495-512.

20. R.W. Armstrong: Mater. Trans., 2014, vol. 55, pp. 2-12

21. C.C. Koch: Nanostructured Mater., 1997, vol. 9, pp. 13-22.

22. C. Suryanarayana: Prog. Mater. Sci., 2001, vol. 46, pp. 1-184.

23. D.B. Witkin and E.J. Lavernia: Prog. Mater. Sci., 2006, vol. 51, pp. $1-60$.

24. R.Z. Valiev, R.K. Islamgaliev, and I.V. Alexandrov: Prog. Mater. Sci., 2000, vol. 45, pp. 103-89.

25. C.C. Koch, T.G. Langdon, and E.J. Lavernia: Metall. Mater. Trans. A, 2017, vol. 48A, pp. 5181-99.

26. C.A. Handwerker and T.M. Pollock: JOM, 2014, vol. 66, pp. $1321-41$.

27. D. Turnbull: Metall. Trans. A, 1981, vol. 12, pp. 695-708.

28. G. Martin and P. Bellon: Solid State Phys. - Adv. Res. Appl., 1996, vol. 50, p. $189 * 331$.

29. T. Konkova, S. Mironov, A. Korznikov, and S.L. Semiatin: Acta Mater., 2010, vol. 58, pp. 5262-73.

30. K.X. Wei, Z.Q. Chu, W. Wei, Q.B. Du, I.V. Alexandrov, and J. Hu: Adv. Eng. Mater., 2019, vol. 21, pp. 1-8.

31. Y.S. Li, N.R. Tao, and K. Lu: Acta Mater., 2008, vol. 56, pp. $230-41$.

32. B. Zheng, D. Zhang, Y. Zhou, S.N. Mathaudhu, D. Kapoor, J. Paras, and E.J. Lavernia: Advances in Powder Metallurgy and Particulate Materials-2013, Proceedings of the 2013 International Conference on Powder Metallurgy and Particulate Materials, PowderMet 2013, 2013.

33. R.Z. Valiev, Y. Estrin, Z. Horita, T.G. Langdon, M.J. Zehetbauer, and Y.T. Zhu: JOM, 2006, vol. 58, pp. 33-39.

34. T.G. Langdon: Acta Mater., 2013, vol. 61, pp. 7035-59.

35. X.H. An, S.D. Wu, Z.G. Wang, and Z.F. Zhang: Prog. Mater. Sci., 2019, vol. 101, pp. 1-45.

36. Y. Cao, S. Ni, X. Liao, M. Song, and Y. Zhu: Mater. Sci. Eng. R, 2018, vol. 133, pp. 1-59.

37. M.F. Smith: Cold Spray Mater. Depos. Process Fundam. Appl., 2007, vol. 1911, pp. 43-61.

38. Y. Estrin and A. Vinogradov: Acta Mater., 2013, vol. 61, pp. $782-817$

39. R.Z. Valiev and T.G. Langdon: Prog. Mater. Sci., 2006, vol. 51, pp. 881-981.

40. A.P. Zhilyaev and T.G. Langdon: Prog. Mater. Sci., 2008, vol. 53, pp. 893-979.

41. D. Yadav and R. Bauri: Mater. Sci. Eng. A, 2012, vol. 539, pp. 85-92.

42. X. Li, W. Tang, A.P. Reynolds, W.A. Tayon, and C.A. Brice: $J$. Mater. Process. Technol., 2016, vol. 229, pp. 191-98.

43. Y. Guo, M. Efe, W. Moscoso, D. Sagapuram, K.P. Trumble, and S. Chandrasekar: Scr. Mater., 2012, vol. 66, pp. 235-38. 
44. N.R. Tao, Z.B. Wang, W.P. Tong, M.L. Sui, J. Lu, and K. Lu: Acta Mater., 2002, vol. 50, pp. 4603-16.

45. W.L. Li, N.R. Tao, and K. Lu: Scr. Mater., 2008, vol. 59, pp. $546-49$.

46. H.J. Fecht, E. Hellstern, Z. Fu, and W.L. Johnson: Metall. Trans. A, 1990, vol. 21, pp. 2333-37.

47. H.J. Fecht: Nanostructured Mater., 1995, vol. 6, pp. 33-42.

48. N. Hansen and R.F. Mehl: Metall. Mater. Trans. A, 2001, vol. 32A, pp. 2917-35.

49. E. Arzt: Acta Mater., 1998, vol. 46, pp. 5611-26.

50. J. He and E.J. Lavernia: J. Mater. Res., 2001, vol. 16, pp. $2724-32$.

51. Y. Xun, E. Lavernia, and F.A. Mohamed: Metall. Mater. Trans. $A$, 2004, vol. 35A, pp. 573-81.

52. Y.T. Zhu, X.Z. Liao, and X.L. Wu: Prog. Mater. Sci., 2012, vol. 57, pp. 1-62.

53. Y.T. Zhu, X.L. Wu, X.Z. Liao, J. Narayan, L.J. Kecskés, and S.N. Mathaudhu: Acta Mater., 2011, vol. 59, pp. 812-21.

54. M. Dao, L. Lu, R.J. Asaro, J.T.M. De Hosson, and E. Ma: Acta Mater., 2007, vol. 55, pp. 4041-65.

55. R.Z. Valiev, I.V. Alexandrov, Y.T. Zhu, and T.C. Lowe: $J$. Mater. Res., 2002, vol. 17, pp. 5-8.

56. Y.T. Zhu and X. Liao: Nat. Mater., 2004, vol. 3, pp. 351-52.

57. H. Wu and G. Fan: Prog. Mater. Sci., 2020, vol. 113, p. 100675.

58. Q. Wei, B.E. Schuster, S.N. Mathaudhu, K.T. Hartwig, L.J. Kecskes, R.J. Dowding, and K.T. Ramesh: Mater. Sci. Eng. A, 2008, vol. 493, pp. 68-64.

59. Q. Wei, K.T. Ramesh, L.J. Kecskes, S.N. Mathaudhu, and K.T. Hartwig: Mater. Sci. Forum, 2008, vol. 579, pp. 75-90.

60. F.A. Mohamed and Y. Li: Mater. Sci. Eng. A, 2001, vol. 298, pp. $1-15$.

61. H.A. Padilla and B.L. Boyce: Exp. Mech., 2010, vol. 50, pp. 5-23.

62. M.A. Meyers, A. Mishra, and D.J. Benson: Prog. Mater. Sci., 2006, vol. 51, pp. 427-556.

63. I.A. Ovid'ko, R.Z. Valiev, and Y.T. Zhu: Prog. Mater. Sci., 2018, vol. 94 , pp. $462-540$.

64. M. Legros, D.S. Gianola, and K.J. Hemker: Acta Mater., 2008, vol. 56 , pp. $3380-93$.

65. T.J. Rupert, D.S. Gianola, Y. Gan, and K.J. Hemker: Science, 2009, vol. 326, pp. 1686-90.

66. D.S. Gianola, S. Van Petegem, M. Legros, S. Brandstetter, H. Van Swygenhoven, and K.J. Hemker: Acta Mater., 2006, vol. 54 , pp. 2253-63.

67. Y. Huang, S. Sabbaghianrad, A.I. Almazrouee, K.J. AlFadhalah, S.N. Alhajeri, and T.G. Langdon: Mater. Sci. Eng. A, 2016, vol. 656, pp. 55-66.

68. T. Konkova, S. Mironov, A. Korznikov, and S.L. Semiatin: Scr. Mater., 2010, vol. 63, pp. 921-24.

69. M.R. He, S.K. Samudrala, G. Kim, P.J. Felfer, A.J. Breen, J.M. Cairney, and D.S. Gianola: Nat. Commun., 2016, vol. 7, pp. 1-9.

70. T. Konkova, S. Mironov, A. Korznikov, and S.L. Semiatin: Mater. Sci. Eng. A, 2011, vol. 528, pp. 7432-43.

71. J.E. Burke and D. Turnbull: Prog. Met. Phys., 1952, vol. 3, pp. 220-92.

72. S. Simoes, R. Calinas, M.T. Vieira, M.F. Vieira, and P.J. Ferreira: Nanotechnology, 2010, vol. 21, p. 145701.

73. S. Simões, R. Calinas, P.J. Ferreira, F. Viana, M.T. Vieira, and M.F. Vieira: Microsc. Microanal., 2008, vol. 14, pp. 49-52.

74. J.C.M. Li: Phys. Rev. Lett., 2006, vol. 96, p. 215506.

75. J. Weissmüller: Nanostructured Mater., 1993, vol. 3, pp. 261-72.

76. J. Weissmüller: Mater. Sci. Eng. A, 1994, vols. 179-180, pp. 102-07.

77. J. Weissmuller: J. Mater. Res., 1994, vol. 9, pp. 4-7.

78. R. Kirchheim: Acta Mater., 2002, vol. 50, pp. 413-19.

79. C.E. Krill, H. Ehrhardt, and R. Birringer: Z. Met. Res. Adv. Tech., 2005, vol. 96, pp. 1134-41.

80. L.B. Hong, C. Bansal, and B. Fultz: Nanostructured Mater., 1994, vol. 4, pp. 949-56.

81. Z.Q. Gao and B. Fultz: Nanostructured Mater., 1994, vol. 4, pp. 939-47.

82. J.W. Cahn: Acta Metall., 1962, vol. 10, pp. 789-98.

83. A. Khalajhedayati, Z. Pan, and T.J. Rupert: Nat. Commun., 2016, vol. 7, pp. 1-8.

84. J. Li, J. Wang, and G. Yang: Scr. Mater., 2009, vol. 60, pp. $945-48$.
85. J.R. Trelewicz and C.A. Schuh: Phys. Rev. B, 2009, vol. 79, p. 094112.

86. S.A. Kube, W. Xing, A. Kalidindi, S. Sohn, A. Datye, D. Amram, C.A. Schuh, and J. Schroers: Acta Mater., 2020, vol. 188 , pp. $40-48$.

87. K.A. Darling, A.J. Roberts, Y. Mishin, S.N. Mathaudhu, and L.J. Kecskes: J. Alloys Compd., 2013, vol. 573, pp. 142-50.

88. K.A. Darling, B.G. Butler, H.E. Maupin, L.J. Kecskes, and S.N. Mathaudhu: Advances in Powder Metallurgy and Particulate Materials-2012, Proceedings of the 2012 International Conference on Powder Metallurgy and Particulate Materials, PowderMet 2012, 2012.

89. K.A. Darling, B.K. VanLeeuwen, C.C. Koch, and R.O. Scattergood: Mater. Sci. Eng. A, 2010, vol. 527, pp. 3572-80.

90. M.A. Atwater, D. Roy, K.A. Darling, B.G. Butler, R.O. Scattergood, and C.C. Koch: Mater. Sci. Eng. A, 2012, vol. 558, pp. 226-33.

91. A. Devaraj, W. Wang, R. Vemuri, L. Kovarik, X. Jiang, M. Bowden, J.R. Trelewicz, S. Mathaudhu, and A. Rohatgi: Acta Mater., 2019, vol. 165, pp. 698-708.

92. A.R. Kalidindi and C.A. Schuh: Acta Mater., 2017, vol. 132, pp. 128-37.

93. T. Chookajorn, H.A. Murdoch, and C.A. Schuh: Science, 2012, vol. 337 , pp. $951-54$

94. D. Amram and C.A. Schuh: Scr. Mater., 2020, vol. 180, pp. 57-61.

95. C.C. Koch, R.O. Scattergood, K.A. Darling, and J.E. Semones: J. Mater. Sci., 2008, vol. 43, pp. 7264-72.

96. B.S. Murty and S. Ranganathan: Int. Mater. Rev., 1998, vol. 43, pp. $101-41$

97. F. Abdeljawad, P. Lu, N. Argibay, B.G. Clark, B.L. Boyce, and S.M. Foiles: Acta Mater., 2017, vol. 126, pp. 528-39.

98. C.J. O'Brien, C.M. Barr, P.M. Price, K. Hattar, and S.M. Foiles: J. Mater. Sci., 2018, vol. 53, pp. 2911-27.

99. M.A. Tschopp, H.A. Murdoch, L.J. Kecskes, and K.A. Darling: JOM, 2014, vol. 66, pp. 1000-19.

100. C.M. Grigorian and T.J. Rupert: Acta Mater., 2019, vol. 179, pp. $172-82$.

101. J. Ding, Z. Shang, Y.F. Zhang, R. Su, J. Li, H. Wang, and X. Zhang: Scr. Mater., 2020, vol. 182, pp. 21-26.

102. E. Ma: Prog. Mater. Sci., 2005, vol. 50, pp. 413-509.

103. S.N. Mathaudhu and B.L. Boyce: JOM, 2015, vol. 67, pp. 2785-87.

104. G.H. Balbus, M.P. Echlin, C.M. Grigorian, T.J. Rupert, T.M. Pollock, and D.S. Gianola: Acta Mater., 2018, vol. 156, pp. $183-95$.

105. J.F. Curry, T.F. Babuska, T.A. Furnish, P. Lu, D.P. Adams, A.B. Kustas, B.L. Nation, M.T. Dugger, M. Chandross, B.G. Clark, B.L. Boyce, C.A. Schuh, and N. Argibay: $A d v$. Mater., 2018, vol. 30, p. 1802026.

106. K.A. Darling, M. Rajagopalan, M. Komarasamy, M.A. Bhatia, B.C. Hornbuckle, R.S. Mishra, and K.N. Solanki: Nature, 2016, vol. 537 , pp. $378-81$.

107. S.A. Turnage, M. Rajagopalan, K.A. Darling, P. Garg, C. Kale, B.G. Bazehhour, I. Adlakha, B.C. Hornbuckle, C.L. Williams, P. Peralta, and K.N. Solanki: Nat. Commun., 2018, vol. 9, pp. $1-10$.

108. D.E. Spearot, G.J. Tucker, A. Gupta, and G.B. Thompson: $J$. Appl. Phys., 2019, vol. 126, p. 110901.

109. H.R. Peng, M.M. Gong, Y.Z. Chen, and F. Liu: Int. Mater. Rev., 2017, vol. 52, pp. 303-33.

110. F. Endres, M. Bukowski, R. Hempelmann, and H. Natter: Angew. Chem. Int. Ed., 2003, vol. 42, pp. 3428-30.

111. T.J. Rupert and C.A. Schuh: Acta Mater., 2010, vol. 58, pp. 4137-48.

112. M. Jin, P. Cao, S. Yip, and M.P. Short: Acta Mater., 2018, vol. 155 , pp. $410-17$.

113. J.D. Schuler, C.M. Grigorian, C.M. Barr, B.L. Boyce, K. Hattar, and T.J. Rupert: Acta Mater., 2020, vol. 186, pp. 341-54.

114. K. Abiko: Mater. Trans., 2000, vol. 41, pp. 233-37.

115. M. Kato: JOM, 1995, vol. 47, pp. 44-46.

116. S. Fujiwara and K. Abiko: J. Phys. IV, 1995, vol. 5, pp. C7-295-C7-300.

117. C. Ouchi, H. Iizumi, and S. Mitao: Mater. Sci. Eng. A, 1998, vol. 243, pp. 186-95. 
118. T.R. Malow and C.C. Koch: Mater. Sci. Forum, 1996, vols. 225-227, pp. 595-604.

119. C.H. Moelle and H.J. Fecht: Nanostructured Mater., 1995, vol. 6, pp. 421-24.

120. K. Zhang, J.R. Weertman, and J.A. Eastman: Appl. Phys. Lett., 2005, vol. 87, p. 061921.

121. C. Smith: Trans. AIME, 1948, vol. 175, pp. 15-51.

122. T. Nishizawa, I. Ohnuma, and K. Ishida: Mater. Trans., 1997, vol. 38 , pp. $950-56$

123. J.E. Burke: Trans. AIME, 1948, vol. 180, pp. 73-91.

124. A. Michels, C.E. Krill, H. Ehrhardt, R. Birringer, and D.T. Wu: Acta Mater., 1999, vol. 47, pp. 2143-52.

125. K. Edalati, J.M. Cubero-Sesin, A. Alhamidi, I.F. Mohamed, and Z. Horita: Mater. Sci. Eng. A, 2014, vol. 613, pp. 103-10.

126. D.S. Gianola, B.G. Mendis, X.M. Cheng, and K.J. Hemker: Mater. Sci. Eng. A, 2008, vols. 483-484, pp. 637-40.

127. M.-R. He, S.K. Samudrala, G. Kim, P.J. Felfer, A.J. Breen, J.M. Cairney, and D.S. Gianola: Nat. Commun., 2016, vol. 7, pp. 1-9.

128. H. Wen, Y. Zhao, Z. Zhang, O. Ertorer, S. Dong, and E.J. Lavernia: J. Mater. Sci., 2011, vol. 46, pp. 3006-12.

129. H. Kotan, K.A. Darling, R.O. Scattergood, and C.C. Koch: $J$. Alloys Compd., 2014, vol. 615, pp. 1013-18.

130. Y.J. Hu, J. Li, K.A. Darling, W.Y. Wang, B.K. Vanleeuwen, X.L. Liu, L.J. Kecskes, E.C. Dickey, and Z.K. Liu: Sci. Rep., 2015, vol. 5, pp. 1-9.

131. M. Kapoor, T. Kaub, K.A. Darling, B.L. Boyce, and G.B. Thompson: Acta Mater., 2017, vol. 126, pp. 564-75.

132. C.J. Marvel, D. Yin, P.R. Cantwell, and M.P. Harmer: Mater. Sci. Eng. A, 2016, vol. 664, pp. 49-57.

133. J. Guo, G. Haberfehlner, J. Rosalie, L. Li, M.J. Duarte, G. Kothleitner, G. Dehm, Y. He, R. Pippan, and Z. Zhang: Nat. Commun., 2018, vol. 9, p. 946.

134. K.K. Schulze: J. Met., 1981, vol. 33, pp. 33-41.

135. Y.Z. Chen, K. Wang, G.B. Shan, A.V. Ceguerra, L.K. Huang, H. Dong, L.F. Cao, S.P. Ringer, and F. Liu: Acta Mater., 2018, vol. 158 , pp. $340-53$

136. W.Z. Xu, L.L. Li, M. Saber, C.C. Koch, Y.T. Zhu, and R.O. Scattergood: J. Nucl. Mater., 2014, vol. 452, pp. 434-39.

137. W. Xu, L. Li, M. Saber, C.C. Koch, Y. Zhu, and R.O Scattergood: Metall. Mater. Trans. A, 2015, vol. 46A, pp. 4394-4404.

138. Y. Lin, H. Wen, Y. Li, B. Wen, W. Liu, and E.J. Lavernia: Metall. Mater. Trans. A, 2014, vol. 45A, pp. 2673-88.

139. X. Zhou, X.Y. Li, and K. Lu: Science, 2018, vol. 360, pp. 526-30.

140. J. Guo, M.J. Duarte, Y. Zhang, A. Bachmaier, C. Gammer, G. Dehm, R. Pippan, and Z. Zhang: Acta Mater., 2019, vol. 166, pp. 281-93.

141. E.J. Lavernia, B.Q. Han, and J.M. Schoenung: Mater. Sci. Eng. A, 2008, vol. 493, pp. 207-14

142. P. Callahan, J.-C. Stinville, E. Yao, M.P. Echlin, J. Shin, F. Wang, M. De Graef, T.M. Pollock, and D.S. Gianola: $M i-$ crosc. Microanal., 2018, vol. 24, pp. 1836-37.

143. M. Legros, B.R. Elliott, M.N. Rittner, J.R. Weertman, and K.J. Hemker: Philos. Mag. A, 2000, vol. 80, pp. 1017-26.

144. S.H. Oh, M. Legros, D. Kiener, and G. Dehm: Nat. Mater., 2009, vol. 8 , pp. $95-100$.

145. G.C. Sneddon, P.W. Trimby, and J.M. Cairney: Mater. Sci. Eng. $R, 2016$, vol. 110 , pp. 1-12.

146. M. Legros: C. R. Phys., 2014, vol. 15, pp. 224-40.

147. F. Mompiou, M. Legros, and D. Caillard: J. Mater. Sci., 2011, vol. 46, pp. 4308-13.

148. Y.B. Wang, B.Q. Li, M.L. Sui, and S.X. Mao: Appl. Phys. Lett., 2008, vol. 92, pp. 2006-09.

149. H. Van Swygenhoven: Science (80-.)., 2002, vol. 296, pp. 66-7.

150. K.S. Kumar, H. Van Swygenhoven, and S. Suresh: Acta Mater., 2003, vol. 51, pp. 5743-74.

151. C.M.F. Rae and D.A. Smith: Philos. Mag. A, 1980, vol. 41, pp. 477-92.

152. J.P. Hirth, G. Hirth, and J. Wang: Proc. Natl. Acad. Sci. USA, 2020, vol. 117, pp. 196-204.

153. S.L. Thomas, K. Chen, J. Han, P.K. Purohit, and D.J. Srolovitz: Nat. Commun., 2017, vol. 8, pp. 1-12.
154. A. Rajabzadeh, F. Mompiou, M. Legros, and N. Combe: Phys. Rev. Lett., 2013, vol. 110, pp. 1-5.

155. A. Rajabzadeh, F. Mompiou, S. Lartigue-Korinek, N. Combe, M. Legros, and D.A. Molodov: Acta Mater., 2014, vol. 77, pp. 223-35.

156. S. Gourdet and F. Montheillet: Acta Mater., 2002, vol. 50, pp. 2801-12.

157. Q. Zhu, G. Cao, J. Wang, C. Deng, J. Li, Z. Zhang, and S.X. Mao: Nat. Commun., 2019, vol. 10, pp. 1-8.

158. A. Vinogradov and Y. Estrin: Prog. Mater. Sci., 2018, vol. 95 , pp. $172-242$

159. D. Raabe, M. Herbig, S. Sandlöbes, Y. Li, D. Tytko, M. Kuzmina, D. Ponge, and P.P. Choi: Curr. Opin. Solid State Mater. Sci., 2014, vol. 18, pp. 253-61.

160. T.J. Rupert, J.C. Trenkle, and C.A. Schuh: Acta Mater., 2011, vol. 59, pp. 1619-31.

161. S. Yip: Nature, 1998, vol. 391, pp. 532-33.

162. A.S. Argon and S. Yip: Philos. Mag. Lett., 2006, vol. 86, pp. 713-20.

163. J.R. Weertman, D. Farkas, K. Hemker, H. Kung, M. Mayo, R. Mitra, and H. Van Swygenhoven: MRS Bull., 1999, vol. 24, pp. $44-53$.

164. J.R. Trelewicz and C.A. Schuh: Acta Mater., 2007, vol. 55, pp. $5948-58$.

165. M. Jiang, B. Devincre, and G. Monnet: Int. J. Plast., 2019, vol. 113 , pp. 111-24

166. J.C.M. Li: Trans. Metall. Soc. AIME, 1963, vol. 227, p. 239.

167. J.D. Embury and R.M. Fisher: Acta Metall., 1966, vol. 14, pp. 147-59.

168. T.G. Nieh and J. Wadsworth: Scr. Metall. Mater., 1991, vol. 25, pp. $955-58$.

169. J.R. Weertman: MRS Bull., 2004, vol. 29, pp. 616-20.

170. A.H. Chokshi, A. Rosen, J. Karch, and H. Gleiter: Scr. Metall., 1989, vol. 23, pp. 1679-83.

171. M.A. Meyers, A. Mishra, and D.J. Benson: JOM, 2006, vol. 58, pp. $41-48$.

172. H. Conrad: Metall. Mater. Trans. A, 2004, vol. 35A, pp. 2681-95.

173. D.L. Holt: J. Appl. Phys., 1970, vol. 41, pp. 3197-3201.

174. M.R. Staker and D.L. Holt: Acta Metall., 1972, vol. 20, pp. 569-79.

175. J. Schiøtz and K.W. Jacobsen: Science, 2003, vol. 301, pp. 1357-59.

176. H. Van Swygenhoven and P.M. Derlet: Phys. Rev. B, 2001, vol. 64 , pp. $1-9$.

177. V. Yamakov, D. Wolf, S.R. Phillpot, A.K. Mukherjee, and H. Gleiter: Philos. Mag. Lett., 2003, vol. 83, pp. 385-93.

178. M.Y. Gutkin and I.A. Ovid'ko: Appl. Phys. Lett., 2005, vol. 87, p. 251916.

179. L. Wang, J. Teng, P. Liu, A. Hirata, E. Ma, Z. Zhang, M. Chen, and X. Han: Nat. Commun., 2014, vol. 5, pp. 1-7.

180. K. Lu: Mater. Sci. Eng. R, 1996, vol. 16, pp. 161-221.

181. N.X. Sun and K. Lu: Phys. Rev. B, 1999, vol. 59, pp. 5987-89.

182. V. Mote, Y. Purushotham, and B. Dole: J. Theor. Appl. Phys., 2012, vol. 6, pp. 2-9.

183. K. He, N. Chen, C. Wang, L. Wei, and J. Chen: Cryst. Res. Technol., 2018, vol. 53, pp. 1-6.

184. N. Hansen: Scr. Mater., 2004, vol. 51, pp. 801-06.

185. S.N. Naik and S.M. Walley: J. Mater. Sci., 2020, vol. 55, pp. 2661-81.

186. J. Schäfer and K. Albe: Acta Mater., 2012, vol. 60, pp. 6076-85.

187. S. Özerinç, K. Tai, N.Q. Vo, P. Bellon, R.S. Averback, and W.P. King: Scr. Mater., 2012, vol. 67, pp. 720-23.

188. N.Q. Vo, J. Schäfer, R.S. Averback, K. Albe, Y. Ashkenazy, and P. Bellon: Scr. Mater., 2011, vol. 65, pp. 660-63.

189. I.M. Hutchings: J. Mater. Res., 2009, vol. 24, pp. 581-89.

190. I. Brooks, P. Lin, G. Palumbo, G.D. Hibbard, and U. Erb: Mater. Sci. Eng. A, 2008, vol. 491, pp. 412-19.

191. P. Zhang, S.X. Li, and Z.F. Zhang: Mater. Sci. Eng. A, 2011, vol. 529 , pp. $62-73$.

192. H. Hahn, P. Mondal, and K.A. Padmanabhan: Nanostructured Mater., 1997, vol. 9, pp. 603-06.

193. D. Wolf, V. Yamakov, S.R. Phillpot, A. Mukherjee, and H. Gleiter: Acta Mater., 2005, vol. 53, pp. 1-40.

194. D.A. Konstantinidis and E.C. Aifantis: Nanostructured Mater., 1998, vol. 10, pp. 1111-18. 
195. X. Zhang and K.E. Aifantis: J. Mater. Res., 2011, vol. 26, pp. 1399-1405.

196. M. Chandross: Phys. Rev. Lett., 2020, vol. 124, p. 125501.

197. C.A. Schuh: Physics, 2020, vol. 13, p. 42.

198. N.F. Mott: Proc. Phys. Soc., 1948, vol. 60, pp. 391-94.

199. G. Gottstein and L.S. Shvindlerman: Grain Boundary Migration in Metals, CRC Press, Boca Raton, 2009.

200. H. Zheng, X.G. Li, R. Tran, C. Chen, M. Horton, D. Winston, K.A. Persson, and S.P. Ong: Acta Mater., 2020, vol. 186, pp. $40-49$

201. M. McLean: J. Mater. Sci., 1973, vol. 8, pp. 571-76.

202. K.I. Ikeda, K. Yamada, N. Takata, F. Yoshida, H. Nakashima, and N. Tsuji: Mater. Trans., 2008, vol. 49, pp. 24-30.

203. R.E. Riecker and L.C. Towle: J. Appl. Phys., 1967, vol. 38, pp. 5189-94.

204. K. Edalati and Z. Horita: Mater. Sci. Eng. A, 2011, vol. 528, pp. 7514-23.

205. K.M. Youssef, R.O. Scattergood, K.L. Murty, and C.C. Koch: Appl. Phys. Lett., 2004, vol. 85, pp. 929-31.

206. J. Liu, H. Cui, X. Zhou, and J. Zhang: Mater. Trans., 2012, vol. 53 , pp. $766-69$.

207. T.J. Rupert: Scr. Mater., 2014, vol. 81, pp. 44-47.

208. P.R. Cantwell, T. Frolov, T.J. Rupert, A.R. Krause, C.J. Marvel, G.S. Rohrer, J.M. Rickman, and M.P. Harmer: Annu. Rev. Mater. Res., 2020, vol. 50, p. 465.

209. J. Eckert, J.C. Holzer, C.E. Krill, and W.L. Johnson: J. Mater. Res., 1992, vol. 7, pp. 1751-61.

210. D. Oleszak and P.H. Shingu: J. Appl. Phys., 1996, vol. 79, pp. 2975-80.

211. F.A. Mohamed: Acta Mater., 2003, vol. 51, pp. 4107-19.

212. F.A. Mohamed and S.S. Dheda: Mater. Sci. Eng. A, 2012, vol. 558, pp. $59-63$.

213. F.A. Mohamed and S.S. Dheda: Mater. Sci. Eng. A, 2013, vol. 580 , pp. 227-30.

214. F.A. Mohamed: Mater. Sci. Eng. A, 2010, vol. 527, pp. 2157-62.

215. F.A. Mohamed: Mater. Sci. Eng. A, 2019, vol. 752, pp. 15-17.

216. K. Edalati and Z. Horita: Acta Mater., 2011, vol. 59, pp. 6831-36.

217. R. Pippan, F. Wetscher, M. Hafok, A. Vorhauer, and I. Sabirov: Adv. Eng. Mater., 2006, vol. 8, pp. 1046-56.

218. Y.H. Zhao, X.Z. Liao, Y.T. Zhu, Z. Horita, and T.G. Langdon: Mater. Sci. Eng. A, 2005, vols. 410-411, pp. 188-93.

219. N. Balasubramanian and T.G. Langdon: Metall. Mater. Trans. A, 2016, vol. 47A, pp. 5827-38.

220. R.Z. Valiev: Mater. Trans., 2014, vol. 55, pp. 13-18.

221. S. Lu, Q.M. Hu, E.K. Delczeg-Czirjak, B. Johansson, and L. Vitos: Acta Mater., 2012, vol. 60, pp. 4506-13.

222. R.W. Siegel: MRS Bull., 1990, vol. 15, pp. 60-67.

223. R.Z. Valiev, V.Y. Gertsman, and O.A. Kaibyshev: Phys. Status Solidi, 1983, vol. 78, pp. 177-86.

224. J.Y. Huang, Y.T. Zhu, H. Jiang, and T.C. Lowe: Acta Mater., 2001, vol. 49, pp. 1497-505.

225. X. Sauvage, G. Wilde, S.V. Divinski, Z. Horita, and R.Z. Valiev: Mater. Sci. Eng. A, 2012, vol. 540, pp. 1-12.

226. R.Z. Valiev, N.A. Enikeev, M.Y. Murashkin, V.U. Kazykhanov, and X. Sauvage: Scr. Mater., 2010, vol. 63, pp. 949-52.

227. G. Wilde and S. Divinski: Mater. Trans., 2019, vol. 60 , pp. $1302-15$.

228. A. Bachmaier and R. Pippan: Mater. Trans., 2019, vol. 60 , pp. $1256-69$.

229. T. Meiners, T. Frolov, R.E. Rudd, G. Dehm, and C.H. Liebscher: Nature, 2020, vol. 579, pp. 375-78.

230. E. Rabkin: Nature, 2020, vol. 579, pp. 350-51.

231. M. Aramfard and C. Deng: Acta Mater., 2018, vol. 146, pp. 304-13.

232. S.J. Dillon, K. Tai, and S. Chen: Curr. Opin. Solid State Mater. Sci., 2016, vol. 20, pp. 324-35.

233. M. Chandross, J.F. Curry, T.F. Babuska, P. Lu, T.A. Furnish, A.B. Kustas, B.L. Nation, W.L. Staats, and N. Argibay: Scr. Mater., 2018, vol. 143, pp. 54-58.

234. J. Hu, Y.N. Shi, X. Sauvage, G. Sha, and K. Lu: Science, 2017, vol. 355 , pp. 1292-96.

235. J. Schiøtz, F.D. Di Tolla, and K.W. Jacobsen: Nature, 1998, vol. 391, pp. 561-63.
236. T.J. Rupert and C.A. Schuh: Philos. Mag. Lett., 2012, vol. 92, pp. 20-28.

237. Y. Buranova, H. Rösner, S.V. Divinski, R. Imlau, and G. Wilde: Acta Mater., 2016, vol. 106, pp. 367-73.

238. C. Ernould, B. Beausir, J.J. Fundenberger, V. Taupin, E. Bouzy: Scr. Mater., 2020, vol. 185, pp. 30-35.

239. R. Maaß and P.M. Derlet: Acta Mater., 2018, vol. 143, pp. $338-63$.

240. M. Stückler, H. Krenn, R. Pippan, L. Weissitsch, S. Wurster, and A. Bachmaier: Nanomaterials, 2019, vol. 9, pp. 1-8.

241. Z. Liao, M. Polyakov, O.G. Diaz, D. Axinte, G. Mohanty, X. Maeder, J. Michler, and M. Hardy: Acta Mater., 2019, vol. 180 , pp. $2-14$

242. M.F. Ashby: Materials Selection in Mechanical Design, 3rd ed., Elsevier, London, 2005.

243. Z. Liu, G. Han, S. Sohn, N. Liu, and J. Schroers: Phys. Rev. Lett., 2019, vol. 122, p. 36101.

244. S.N. Mathaudhu: Physics, 2019, vol. 12, p. 3

245. L. Xu, L. Shui, Y. Zhang, Q. Peng, L. Xue, and Z. Liu: Appl. Phys. Express, 2020, vol. 13, p. 036502.

246. Z. Yin, X. Yang, X. Ma, J. Moering, J. Yang, Y. Gong, Y. Zhu, and X. Zhu: Mater. Des., 2016, vol. 105, pp. 89-95.

247. S. Shahrezaei, Y. Sun, and S.N. Mathaudhu: Mater. Sci. Eng. A, 2019, vol. 761, p. 138023 .

248. J. Moering, X. Ma, G. Chen, P. Miao, G. Li, G. Qian, S. Mathaudhu, and Y. Zhu: Scr. Mater., 2015, vol. 108, pp. 100-13.

249. Y. Liu, Y. Cao, H. Zhou, X. Chen, Y. Liu, L. Xiao, X. Huan, Y. Zhao, and Y. Zhu: Adv. Eng. Mater., 2020, vol. 22, pp. 1-8.

250. D. Orlov, H. Fujiwara, and K. Ameyama: Mater. Trans., 2013, vol. 54 , pp. $1549-53$

251. S.K. Vajpai, M. Ota, Z. Zhang, and K. Ameyama: Mater. Res. Lett., 2016, vol. 4, pp. 191-97.

252. X. Wu and Y. Zhu: Mater. Res. Lett., 2017, vol. 5, pp. 527-32.

253. X. Wu, M. Yang, F. Yuan, G. Wu, Y. Wei, X. Huang, and Y. Zhu: Proc. Natl. Acad. Sci. USA, 2015, vol. 112, pp. 14501-05.

254. E. Ma and T. Zhu: Mater. Today, 2017, vol. 20, pp. 323-31.

255. Y. Liu, Y. Cao, Q. Mao, H. Zhou, Y. Zhao, W. Jiang, Y. Liu, J.T. Wang, Z. You, and Y. Zhu: Acta Mater., 2020, vol. 189, pp. $129-44$

256. Y. Zhu and X. Wu: Mater. Res. Lett., 2019, vol. 7, pp. 393-98.

257. R.S. Mishra and Z.Y. Ma: Mater. Sci. Eng. R, 2005, vol. 50, pp. $1-78$.

258. M. Rokni, S.R. Nutt, C.A. Widener, V.K. Champagne, and R.H. Hrabe: J. Therm. Spray Technol., 2017, vol. 26, pp. $1308-55$.

259. V. Champagne and D. Helfritch: Int. Mater. Rev., 2016, vol. 61, pp. $437-55$

260. A. Moridi, S.M. Hassani-Gangaraj, M. Guagliano, and M. Dao: Surf. Eng., 2014, vol. 30, pp. 369-95.

261. J.R. Croteau, J.G. Jung, S.A. Whalen, J. Darsell, A. Mello, D. Holstine, K. Lay, M. Hansen, D.C. Dunand, and N.Q. Vo: Scr. Mater., 2020, vol. 186, pp. 326-30.

262. A. Menard, C. Gallardo, W.J. Emblom, S.W. Wagner, A. Olayinka, C. Loehn, D. Seguin, and M.A. Wahab: ASME Int. Mech. Eng. Congr. Expo. Proc., 2018, vol. 2, pp. 1-8.

263. S. Mathaudhu, N. Overman, S. Whalen, M. Olszta, D. Catalini, K. Kruska, J. Darsell, V. Joshi, X. Jiang, A. Devaraj, and G. Grant: Magnes. Technol., 2019, vol. 2019, pp. 65-67.

264. S. Whalen, M. Olszta, C. Roach, J. Darsell, D. Graff, M. Reza-E-Rabby, T. Roosendaal, W. Daye, T. Pelletiers, S. Mathaudhu, and N. Overman: Materialia, 2019, vol. 6, p. 100260 .

265. N.R. Overman, S.A. Whalen, M.E. Bowden, M.J. Olszta, K. Kruska, T. Clark, E.L. Stevens, J.T. Darsell, V.V. Joshi, X. Jiang, K.F. Mattlin, and S.N. Mathaudhu: Mater. Sci. Eng. A, 2017, vol. 701, pp. 56-68.

266. X. Li, N. Overman, T. Roosendaal, M. Olszta, C. Zhou, H. Wang, T. Perry, J. Schroth, and G. Grant: JOM, 2019, vol. 71, pp. 4799-4805.

267. O.G. Rivera, P.G. Allison, J.B. Jordon, O.L. Rodriguez, L.N. Brewer, Z. McClelland, W.R. Whittington, D. Francis, J. Su, R.L. Martens, and N. Hardwick: Mater. Sci. Eng. A, 2017, vol. 694 , pp. $1-9$. 
268. B.J. Phillips, D.Z. Avery, T. Liu, O.L. Rodriguez, C.J.T. Mason, J.B. Jordon, L.N. Brewer, and P.G. Allison: Materialia, 2019 , vol. 7, p. 100387.

269. D.Z. Avery, B.J. Phillips, C.J.T. Mason, M. Palermo, M.B. Williams, C. Cleek, O.L. Rodriguez, P.G. Allison, and J.B. Jordon: Metall. Mater. Trans. A, 2020, vol. 51A, pp. 2778-95.

270. O.G. Rivera, P.G. Allison, L.N. Brewer, O.L. Rodriguez, J.B. Jordon, T. Liu, W.R. Whittington, R.L. Martens, Z. McClelland, C.J.T. Mason, L. Garcia, J.Q. Su, and N. Hardwick: Mater. Sci. Eng. A, 2018, vol. 724, pp. 547-58.

271. J.Q. Su, T.W. Nelson, and C.J. Sterling: Philos. Mag., 2006, vol. 86, pp. 1-24.

272. C.G. Rhodes, M.W. Mahoney, W.H. Bingel, and M. Calabrese: Scr. Mater., 2003, vol. 48, pp. 1451-55.

273. J.Q. Su, T.W. Nelson, and C.J. Sterling: J. Mater. Res., 2003, vol. 18 , pp. 1757-60.

274. X. Du and B. Wu: Sci. China E, 2009, vol. 52, pp. 1751-55.

275. W. Hanna, K. Maung, M. Enayati, J.C. Earthman, and F.A. Mohamed: Mater. Sci. Eng. A, 2019, vol. 746, pp. 290-99.

276. J. Liu, H. Cui, X. Zhou, X. Wu, and J. Zhang: Met. Mater. Int., 2012, vol. 18, pp. 121-28.

277. M. Park and C.A. Schuh: Nat. Commun., 2015, vol. 6, p. 6858.
278. M. Park, T. Chookajorn, and C.A. Schuh: Acta Mater., 2018, vol. 145, pp. 123-33.

279. C. Cao, G. Yao, L. Jiang, M. Sokoluk, X. Wang, J. Ciston, A. Javadi, Z. Guan, I. De Rosa, W. Xie, E.J. Lavernia, J.M. Schoenung, and X. Li: Sci. Adv., 2019, vol. 5, p. eaaw2398.

280. L.-Y. Chen, J.-Q. Xu, H. Choi, M. Pozuelo, X. Ma, S. Bhowmick, J.-M. Yang, S. Mathaudhu, and X.-C. Li: Nature, 2015, vol. 528, pp. 539-43.

281. R.D. MacPherson and D.J. Srolovitz: Nature, 2007, vol. 446, pp. $1053-55$.

282. J. Minkel: Sci. Am., 2007, vol. 297, p. 32.

283. M. Chen: NPG Asia Mater., 2011, vol. 3, pp. 82-90.

284. J.J. Kruzic: Adv. Eng. Mater., 2016, vol. 18, pp. 1308-31.

285. D.B. Miracle and O.N. Senkov: Acta Mater., 2017, vol. 122, pp. $448-511$.

286. E.P. George, D. Raabe, and R.O. Ritchie: Nat. Rev. Mater., 2019, vol. 4, pp. 515-34.

287. E.P. George, W.A. Curtin, and C.C. Tasan: Acta Mater., 2020, vol. 188 , pp. $435-74$.

Publisher's Note Springer Nature remains neutral with regard to jurisdictional claims in published maps and institutional affiliations. 